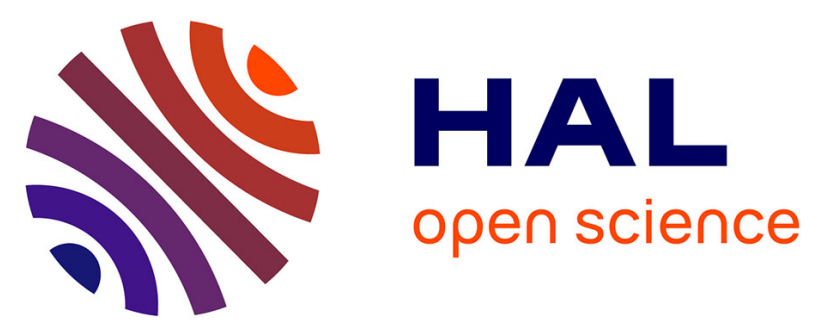

\title{
Direct correlation of nanoscale morphology and device performance to study photocurrent generation in donor enriched phases of polymer solar cells
}

Sadok Ben Dkhil, Pavlo Perkhun, Chieh Luo, David Müller, Riva Alkarsifi, Elena Barulina, Yatzil Alejandra Avalos-Quiroz, Olivier Margeat, Stephan Thierry Dubas, Tomoyuki Koganezawa, et al.

\section{To cite this version:}

Sadok Ben Dkhil, Pavlo Perkhun, Chieh Luo, David Müller, Riva Alkarsifi, et al.. Direct correlation of nanoscale morphology and device performance to study photocurrent generation in donor enriched phases of polymer solar cells. ACS Applied Materials \& Interfaces, 2020, 10.1021/acsami.0c05884 . hal-02775480

\author{
HAL Id: hal-02775480 \\ https://hal.science/hal-02775480
}

Submitted on 6 Oct 2020

HAL is a multi-disciplinary open access archive for the deposit and dissemination of scientific research documents, whether they are published or not. The documents may come from teaching and research institutions in France or abroad, or from public or private research centers.
L'archive ouverte pluridisciplinaire HAL, est destinée au dépôt et à la diffusion de documents scientifiques de niveau recherche, publiés ou non, émanant des établissements d'enseignement et de recherche français ou étrangers, des laboratoires publics ou privés. 


\section{Direct correlation of nanoscale morphology and}

\section{device performance to study photocurrent generation}

\section{in donor enriched phases of polymer solar cells}

Sadok Ben Dkhil, ${ }^{1, \S}$ Pavlo Perkhun, ${ }^{1}$ Chieh Luo, ${ }^{2}$ David Müller, ${ }^{2}$ Riva Alkarsifi, ${ }^{1}$ Elena Barulina, ${ }^{1,3}$ Yatzil Alejandra Avalos Quiroz, ${ }^{1}$ Olivier Margeat, ${ }^{1}$ Stephan Thierry Dubas, ${ }^{4,5}$ Tomoyuki Koganezawa, ${ }^{6}$ Daiki Kuzuhara, ${ }^{7}$ Noriyuki Yoshimoto, ${ }^{7}$ Claudia Caddeo ${ }^{8}$, Alessandro Mattoni ${ }^{8}$ Birger Zimmermann, ${ }^{2}$ Uli Würfel, ${ }^{2,9}$ Martin Pfannmöller, ${ }^{10, \#, *}$ Sara Bals, ${ }^{10}$ Jörg Ackermann, ${ }^{1}$ Christine Videlot-Ackermann ${ }^{1, *}$

${ }^{1}$ Aix Marseille Univ., UMR CNRS 7325, CINaM, 13288 Marseille, France.

${ }^{2}$ Fraunhofer Institute for Solar Energy Systems (ISE), Heidenhofstr. 2, 79110 Freiburg, Germany.

${ }^{3}$ Dracula Technologies, 4 Rue Georges Auric, 26000 Valence, France.

${ }^{4}$ The Petroleum and Petrochemical College, Chulalongkorn University, Bangkok 10330, Thailand.

${ }^{5}$ Center of Excellence on Petrochemical and Materials Technology, Bangkok 10330, Thailand.

${ }^{6}$ Industrial Application Division, Japan Synchrotron Radiation Research Institute (JASRI), Sayo, Hyogo 679-5198, Japan.

${ }^{7}$ Department of Physical Science and Materials Engineering, Iwate University, Ueda Morioka 020 8551, Japan.

${ }^{8}$ Istituto Officina dei Material (CNR-IOM), UOS Cagliari SLACS, Cittadella Universitaria, I09042 Monserrato, Cagliari, Italy.

${ }^{9}$ Materials Research Center FMF, University of Freiburg, Germany 
${ }^{10}$ Electron Microscopy for Materials Research (EMAT), University of Antwerp, Groenenborgerlaan 171, 2020 Antwerp, Belgium.

KEYWORDS. PTB7:PC 71 BM, blend ratio, solar cell, additive, nanoscale fullerene network, charge transport.

ABSTRACT. The nanoscale morphology of polymer blends is a key parameter to reach high efficiency in bulk heterojunction solar cells. Thereby, research typically focuses on optimal blend morphologies while studying non-optimized blends may give insight into blend design that can be more robust against morphology defects. Here we focus on the direct correlation of morphology and device performance of PTB7:PC ${ }_{71} \mathrm{BM}$ bulk heterojunction (BHJ) blends processed without additive in different donor:acceptor weight ratios. We show that while blends of a 1:1.5 ratio are composed of large donor enriched and fullerene domains beyond exciton diffusion length, reducing the ratio below 1:0.5 leads to blends composed purely of polymer enriched domains. Importantly photocurrent density in such blends can reach values between 45 to $60 \%$ of those reached of fully optimized blend using additives. We provide here a direct visual evidence that fullerenes in the donor enriched domains are not distributed homogeneously but fluctuate locally. To this end, we performed compositional nanoscale morphology analysis of the blend using spectroscopic imaging of low energy-loss electrons in the transmission electron microscope. Charge transport measurement in combination with molecular dynamics simulations show that the fullerene sub-structures inside the polymer phase generate efficient electron transport in the polymer enriched phase. Furthermore, we show that the formation of densely 
packed regions of fullerene inside the polymer phase is driven by the $\mathrm{PTB} 7: \mathrm{PC}_{71} \mathrm{BM}$ enthalpy of mixing. The occurrence of such a nanoscale network of fullerene clusters leads to a reduction of electron trap states and thus efficient extraction of photocurrent inside the polymer domain. Suitable tuning of the polymer acceptor interaction can thus introduce acceptor sub-networks in polymer enriched phases improving the tolerance for high efficiency BHJ towards morphological defects such as donor enriched domains exceeding exciton diffusion length.

\section{INTRODUCTION}

In the ongoing quest for efficient photon-to-electron conversion, polymer-based solar cells (PSCs) have received an enormous amount of attention in renewable energy sources because of their characteristics enabling solution processability, flexibility, large scale and low cost production properties. ${ }^{1-4}$ Recently, the development of novel non fullerene acceptors has allowed to raise the power conversion efficiency (PCE) of PSCs to more than 18\% in single junction devices and $17 \%$ in tandem solar cells. ${ }^{5-7}$ Besides the rise of new acceptor materials, intensive development on active layer structural optimizations, device engineering or morphology control has contributed in obtaining these efficiencies. ${ }^{8-12}$ The photo-active layer of high efficient solar cells is prepared of a mixture of donor polymer and small molecule acceptor with a suitable weight ratio defined as donor:acceptor (D:A) weight ratio leading to the formation of a nanostructured bulk heterojunction (BHJ). To build a high-performance blend, several factors are involved from materials to layers properties such as (i) a broad absorption overlap with the solar spectrum, (ii) balanced and lossless charge transport, (iii) suitable bandgap and energy level

alignment between polymer and acceptor for charge separation and (iv) sufficient intermixing between polymer and acceptor to ensure a bicontinuous network. Typically, it is assumed that the 
optimization of the polymer blend morphology aims at the formation of a large D:A interface for an efficient exciton dissociation in combination with a domain size equal to approximately twice that of the exciton diffusion length. ${ }^{13}$ Parameters controlling nanoscale morphology of BHJs have been addressed in several reviews. ${ }^{14-16}$ The D:A weight ratio in combination with the molecular interaction and miscibility are the major driving forces. Solvent additives have been found to further improve the nanoscale morphology of the blend. ${ }^{17}$ Although blend processing is nowadays well understood, ${ }^{14,16}$ the optimization of a polymer blend is still delicate and specific for each D:A couple. Particularly, large scale and thus industrial processing of organic solar cells demand for photoactive materials that show a tolerance against non-optimized blend morphologies to prevent performance loss. For example, the fabrication of polymer blend containing morphological defects such large donor enriched domains with dimension surpassing typical exciton diffusion length will lead to losses in device performance. Studying polymer blends with such non optimal phase separation can provide precious information about concepts of more robust blend materials that allow extracting electrons towards to acceptor enriched domains without carrier recombination. In order to gain information about exciton dissociation and charge carrier transport in such non-optimized polymer blends, visualization of the nanoscale morphology and acceptor intercalation on polymer domains of BHJ is necessary. Usually indirect measurements of domain size and acceptor intercalation can be applied to gain insight into the nanoscale morphologies by combining real-space imaging techniques as atomic force microscopy (AFM) and scanning electron microscopy (SEM) for surface information with different XRD techniques. ${ }^{18-23}$ There are only few examples of such a correlation of device performance with direct visualization of, for instance, domain sizes or mixed phases. ${ }^{24-26}$ For example, by applying nonlinear statistical analysis to variations in optical excitations measured 
by electron spectroscopic imaging, varying phases, including mixed phase, can be localized at the nanoscale in photoactive blends. ${ }^{25}$ For localized analysis of compositional variations, the near-edge structure in the X-ray absorption signal (NEXAFS) has been used in scanning transmission X-ray microscopy. ${ }^{18,27}$ Unfortunately, the spatial resolution does not allow visualization of domains or phases with features below $10 \mathrm{~nm}$. On the other hand, spectroscopic imaging of low energy-loss electrons in a transmission electron microscope (TEM) enable one to directly correlate a specific nanoscale morphology with device performance. ${ }^{28-29}$ Furthermore direct visualization of non-fullerene acceptors (NFAs) organization inside the polymer blends has been recently demonstrated using analytic TEM. ${ }^{30}$.

In this work we focus on non-optimized polymer blends as a function of D:A weight ratio to study photocurrent generation and nanoscale organization of acceptors in large polymer enriched domains with domain sizes surpassing typical exciton diffusion lengths by applying spectroscopic imaging with scanning transmission electron microscopy (STEM-SI) of the low energy-loss for visualization. Although high efficiency polymer solar cells nowadays have replaced fullerenes by NFAs, the manipulation of their nanoscale morphology is not so trivial and well understood than in the case of fullerene based blends. Furthermore fullerenes are still used in NFA based solar cells as third component in ternary blends making the choice of a fullerene based model system relevant to study blends with morphological defects such as donor enriched domains that are larger than corresponding exciton diffusion lengths. ${ }^{11}$ For these reasons, we select bulk heterojunctions comprising the donor polymer thieno[3,4-b]-thiophenealt-benzodithiophene (PTB7) and the fullerene acceptor [6,6]phenyl $\mathrm{C}_{71}$ butyric acid methyl ester $\left(\mathrm{PC}_{71} \mathrm{BM}\right)$ (Figure 1a) as it allows to generate specific blend morphologies containing large donor enriched domains. ${ }^{29}$ The PTB7:PC 71 BM blend is a well-known model system since cells 
based on PTB7 blended with $\mathrm{PC}_{71} \mathrm{BM}$ were the first cells to overcome a PCE of $7 \%$ in 2010 by using chlorobenzene (CB) with 3\% 1,8-diiodoctane (DIO) as solvents. ${ }^{13}$ Indeed it was shown that solar cells using $\mathrm{PTB} 7: \mathrm{PC}_{71} \mathrm{BM}$ blends yield performance improvement by using inverted device structure, ${ }^{31}$ molecular weight $(\mathrm{Mw})$ and polydispersity index (PDI)) of PTB7, ${ }^{32,33}$ as well as solvent additive, ${ }^{34-36}$ mixed solvent, ${ }^{18,37,38}$ and interface modification. ${ }^{39,40}$ Importantly the device properties depend largely on the processing conditions with a particular control of the photovoltaic performance by adding DIO to the blend solution. ${ }^{13,18,41,42}$ The use of DIO generates a phase-separated structure composed of domain sizes of $\sim 10 \mathrm{~nm}$ constituting a morphology close to an ideal D:A nanometer-scale interpenetrating network. ${ }^{13,17,43}$ In contrast, PTB7:PC 71 BM blends using a weight ratio of 1:1.5 processed without DIO show a strongly non-optimized nanoscale morphology composed of polymer enriched domains and large spherical fullerene domains. ${ }^{29}$ Importantly, DIO free-processed blends containing very large donor and acceptor domains produce solar cells show relatively high photocurrent close to the $60 \%$ of cells with optimal morphology.$^{18}$ By comparing DIO-optimized PTB7:PC 71 BM solar cells using a weight ratio of 1:1.5 with DIO-free processed solar cells, Collins et al. concluded that the large polymer enriched regions are inefficient for the charge separation due to high rate of geminate recombination and therefore dead zones for the photovoltaic conversion. ${ }^{18}$ In a recent work, C. Ho et al. ${ }^{44}$ studied the early stage of D:A electronic interaction in PTB7:PC 71 BM blends processed with DIO demonstrating that electron trapping is the key limiting factor for BHJ solar cells in the low fullerene content regime, while fast improvement in electron mobility was observed for increase in fullerene concentration towards optimal regime. Hence, PTB7:PC $71 \mathrm{BM}$ can be considered as an ideal model system allowing a large variety of blend morphologies depending on the D:A ratio and use of DIO. To elucidate the reason for the large relative 
photocurrent for DIO free cells, a direct visualization of the blends' nanoscale morphology in correlation to device performance is essential.

To this end, we investigated the $\mathrm{PTB} 7: \mathrm{PC}_{71} \mathrm{BM} \mathrm{BHJ}$ system processed without additive via varying the ratio of $\mathrm{PTB} 7$ and $\mathrm{PC}_{71} \mathrm{BM}$ in the active layer $\left(\mathrm{PTB} 7: \mathrm{PC}_{71} \mathrm{BM}\right.$ at 1:1.5, 1:1, 1:0.5, 1:0.25). Optimized DIO-processes solar cells (with ratio 1:1.5) was used as a reference. The ordering of both the polymer and fullerene was inspected via 2D grazing-incidence X-ray diffractometry (2D-GIXD). To investigate the evolution of fullerene clusters and concentration profiles at a resolution of better than $10 \mathrm{~nm}$, the STEM-SI data was fitted to pure signals from PTB7 and $\mathrm{PC}_{71} \mathrm{BM}$. We show that non-linearities through mixing, which were previously determined by machine learning classification, do not hinder this concentration mapping. ${ }^{25}$ Additionally transport studies were combined with molecular dynamics simulations of the polymer-fullerene blends to understand transport properties and the enthalpy of mixing and fullerene dispersion inside the blends. The combination of experimental evidence and simulation reveals that in polymer-enriched phases with about $25 \%$ of fullerenes, sub-10 nm aggregates of $\mathrm{PC}_{71} \mathrm{BM}$ allow for efficient electron transport towards the fullerene enriched domains and hence the observed high photocurrent. This behavior will support rationales on how the tolerance for high efficiency BHJs towards non optimal blend morphologies can be enhanced.

\section{EXPERIMENTAL SECTION}

2.1 Materials. PTB7 was purchased from 1-Material and the fullerene derivative $\mathrm{PC}_{71} \mathrm{BM}$ from Nano-C (95\% purity). The solvent additive 1,8-diiodoctane (DIO) was purchased from SigmaAldrich ( $\mathrm{pb} 167-169^{\circ} \mathrm{C} / 6 \mathrm{mmHg}($ lit.)). $\mathrm{ZnO}$ nanocrystals were prepared as published

elsewhere. ${ }^{45}$ Cluster free $\mathrm{ZnO}$ nanocrystal solutions in isopropanol (at $7.5 \mathrm{mg} / \mathrm{mL}$ ) was prepared 
by transferring the as-synthesized $\mathrm{ZnO}$ nanoparticles (6 $\mathrm{nm}$ as average diameter) from methanol to isopropanol (IPA) mixed with ethanolamine (EA) at $0.2 \mathrm{wt} \%$.

2.2 Solar Cells Fabrication and Characterization. Solar cells using regular device structures were processed as detailed in former works. ${ }^{28,29}$ ITO substrates (purchased from Lumtec, 15 $\mathrm{Ohm} \mathrm{sq}{ }^{-1}$ ) were thoroughly cleaned by sonication in acetone and ethanol followed by rinsing with water and sonication in isopropanol and applying ultraviolet-ozone for $10 \mathrm{~min}$. A thin layer of poly(3,4-PEDOT:PSS) (CLEVIOS ${ }^{\mathrm{TM}}$ AI 4083) was spin-coated on the cleaned ITO precoated glass substrate at the speed of $4000 \mathrm{rpm}$ for $60 \mathrm{~s}$ followed by an annealing step on a hotplate at $140^{\circ} \mathrm{C}$ for 15 min leading to a thickness of $40 \mathrm{~nm}$. The substrates were then transferred to a nitrogen-filled glove box. PTB7:PC ${ }_{71} \mathrm{BM}$ films with different weight ratios $(1: 0.25,1: 0.5,1: 1$ and 1:1.5) were prepared in nitrogen-filled glove box by fixing the PTB7 amount $(10 \mathrm{mg} / \mathrm{mL})$ and varying the $\mathrm{PC}_{71} \mathrm{BM}$ content $(2.5,5,10$ and $15 \mathrm{mg} / \mathrm{mL})$. The spin-coating was done at ambient temperature $\left(21-25^{\circ} \mathrm{C}\right)$ in glove box. The DIO-processed PTB7:PC ${ }_{71} \mathrm{BM}$ solution at a weight ratio of 1:1.5 was prepared by mixing solvents chlorobenzene/1,8-diiodoctane with 97:3\% by volume. The DIO-free $\mathrm{PTB} 7: \mathrm{PC}_{71} \mathrm{BM}$ solutions were prepared by using chlorobenzene as solvent. Finally, an overnight stirring at $65^{\circ} \mathrm{C}$ was employed to finalize the ready-to-use $\mathrm{PTB} 7: \mathrm{PC}_{71} \mathrm{BM}$ blend solutions for the spin-coating solution process. The different solutions were spin-coated with controlled speeds to obtain thin films with equal thickness of $90 \pm 5 \mathrm{~nm}$ (ratio $1: 1.5$ at $\mathrm{rpm}=1800$, ratio $1: 1$ at $\mathrm{rpm}=1500$, ratio $1: 0.5$ at $\mathrm{rpm}=1200$, ratio $1: 0.25$ at $\mathrm{rpm}=$ 1100 and ratio 1:0 at $\mathrm{rpm}=1000$ ). The spin coating time was fixed at $120 \mathrm{sec}$. After dried in vacuum overnight, $\mathrm{ZnO}$-based interfacial layers (ILs) were deposited by spin-coating $\mathrm{ZnO}$ nanocrystal solution on top of active layers at $1500 \mathrm{rpm}$ for $60 \mathrm{~s}$ followed by annealing for $5 \mathrm{~min}$ at $80^{\circ} \mathrm{C}$; all processes were done inside the glove box. To complete the device, aluminum (Al) 
metal electrodes were thermally evaporated (MBRAUN evaporator) at $2 \times 10^{-6}$ Torr to a thickness of $100 \mathrm{~nm}$ using a shadow mask that define the device area of the solar cells to $0.27 \mathrm{~cm}^{2}$.

The current density-voltage $(\mathrm{J}-\mathrm{V})$ characteristics of the solar cells were measured inside the glove box using a Keithley 238 Source Measure Unit and a Newport class AAA 1.5 Global solar simulator (Oriel Sol3ATM model $\mathrm{n}^{\circ}$ 94043A) with an irradiation intensity of $100 \mathrm{~mW} / \mathrm{cm}^{2}$. The light intensity was determined with a Si reference cell (Newport Company, Oriel $n^{\circ}$ 94043A) calibrated by National Renewable Energy Laboratory (NREL). Spectral mismatch factors (M) were calculated according to a standard procedure and a typical $\mathrm{M}$ value of 1.02 was obtained for the PTB7:PC ${ }_{71} \mathrm{BM}$ devices. ${ }^{45}$ The value was used to correct the measured $\mathrm{J}_{\mathrm{sc}}$ values of the solar cells to $\mathrm{J}_{\mathrm{sc}}$ values corresponding to AM1.5G conditions. Shadow masks were used to well-define the illuminated area to $0.27 \times 1.0 \mathrm{~cm}^{2}$. We present the performance of the best devices, whereas average PCEs were obtained with a standard deviation analysis calculated using 6-9 devices.

External quantum efficiency (EQE) measurements were performed in air using a homemade setup consisting of a Keithley 238 Source Measure Unit and Newport monochromator. Light intensity was measured with a calibrated Si-diode from Newport.

2.3 Thin film Characterizations. UV-Vis absorption spectra of $\mathrm{PTB} 7, \mathrm{PC}_{71} \mathrm{BM}$ and blend layers were recorded using a Varian CARY 5000 spectrophotometer.

Polymer blends were further analyzed by 2D grazing-incidence X-ray diffractometry (2D-GIXD) with high-brightness synchrotron radiation at BL19B2 in SPring-8. 2D-GIXD measurements were performed using a high-sensitive 2D X-ray detector (PILATUS 300K). The incident angle and wavelength of X-rays were $0.13^{\circ}$ and $0.100 \mathrm{~nm}$, respectively. 
STEM-SI measurements were performed at $120 \mathrm{kV}$ using a Titan 60-300 microscope (ThermoFisher Scientific, USA) and an Enfinium spectrometer (Gatan/ThermoFisher Scientific, USA). Planar specimens were prepared by floating the photoactive layer onto water and capturing with a holey carbon film (QUANTIFOIL ${ }^{\circledR}$ ) on an electron microscopy grid. To visualize potential small domains in blends of donor:acceptor ratios of 1:0.25 and 1:0.5, layer thicknesses of ca. $50 \mathrm{~nm}$ were used whilst for higher fullerene concentrations with large agglomerates layers with thickness of about $70 \mathrm{~nm}$ were investigated. In a previous work, we qualitatively investigated the nanoscale morphology of $\mathrm{PTB} 7: \mathrm{PC}_{71} \mathrm{BM}$ blends with a thickness of $90 \mathrm{~nm}$ with and without DIO. ${ }^{29}$ Despite the different perspective and only qualitative nature, the general nanoscale morphologies for the ratio 1:1.5 are identical when comparing layers of 90 and $70 \mathrm{~nm}$ thickness. Therefore, we expect that further reduction to a thickness of $50 \mathrm{~nm}$ through higher spin-coating speed and thus faster drying time does not compromise the validity of the morphological analyses in the current work. The lamella and micro-pillar samples were prepared from solar cell devices with a Helios Nanolab 650 (ThermoFisher Scientific, USA). Scanning step sizes for STEM-SI imaging were set to $3 \mathrm{~nm}$ for planar analyses, and to $2 \mathrm{~nm}$ for crosssectional analyses and for the higher resolution map of the 1:0.5 ratio sample in Figure S9. Spectroscopic imaging (SI) data sets were processed using HyperSpy. ${ }^{46}$ To use single scattering spectra and account for thickness variations, all spectra of a data set were processed by Fourier$\log$ deconvolution. Multiple linear least-squares fitting was performed by a custom Python script using the LMFIT package. ${ }^{47}$ As outlined in the supporting information in Table S1 and Figure S8, for theoretical concentrations of different nominal mixing ratios, weight ratios were transformed into (mono-)molecular ratios using molecular weights of $\mathrm{PC}_{71} \mathrm{BM}$ molecules and PTB7 monomers. 


\subsection{Space Charge Limited Current device Fabrication and Measurements. Space Charge}

Limited Current (SCLC) devices require careful choice of the contacts to ensure sufficient injection of the desired carrier, and effective blocking of the other carrier to work like singlecarrier devices. Hole-only and electron-only devices consisted of ITO/PEDOT:PSS/PTB7:PC ${ }_{71} \mathrm{BM} / \mathrm{MoO} / \mathrm{Au}$ and ITO/ZnO/PTB7:PC ${ }_{71} \mathrm{BM} / \mathrm{LiF} / \mathrm{Al}$, respectively. $\mathrm{ZnO}$ was purchased from Avantama. Top metallic electrodes were thermally evaporated (MBRAUN evaporator) at $2 \times 10^{-6}$ Torr to a controlled thickness (13 nm of MoOx, $100 \mathrm{~nm} \mathrm{Au}$, $0.5 \mathrm{~nm} \mathrm{LiF}$ and $100 \mathrm{~nm}$ of $\mathrm{Al}$ ) using a shadow mask that define the device area to $0.09 \mathrm{~cm}^{2}$ and allowed a four-point measurement. The pristine $\mathrm{PTB} 7: \mathrm{PC}_{71} \mathrm{BM}$ solutions were deposited by spincoating at speeds ranging from 600 to $2500 \mathrm{rpm}$ for $120 \mathrm{sec}$. Active layers were subsequently annealed at $80^{\circ} \mathrm{C}$ during 5 minutes. The thickness of thin films deposited on glass substrate was measured with a Veeco Dektak 150 (Table S2).

The measured dark current was fitted using the Murgatroyd expression:

$I=A \mu_{0} \frac{9}{8} \frac{V^{2}}{d^{3}} \varepsilon \varepsilon_{0} \exp \left(0.891 \gamma \sqrt{\frac{V}{d}}\right)$

where $\mathrm{d}$ is the active layer thickness, $\mathrm{A}$ is the active device area, $\varepsilon \varepsilon_{0}$ is the permittivity of the active layer ( $\varepsilon$ is assumed equal to 3.5 and $\varepsilon_{0}$ is the permittivity of free space), and $\mathrm{V}$ is the voltage. $\mu_{0}$ and $\gamma$ are the unknown parameters that will be adjusted to get a good fit, all other parameters are fixed. $\mu_{0}$ is the mobility at low electric fields, and $\gamma$ is a parameter that represents the field dependence of mobility. Measurements and analysis of I-V curves were made following a specific previously reported protocol. ${ }^{48}$ A complete worked example and the corresponding data fitting (Figures S10-S12) is given in the supporting information. 
2.5 Molecular Dynamics Methods. The PTB7 polymer and $\mathrm{PC}_{71} \mathrm{BM}$ fullerene derivative have been modeled using the General Amber Force Field (GAFF), ${ }^{49}$ which has been successfully adopted to describe fully organic as well as hybrid organic-inorganic blends. ${ }^{50-53}$ The atomic partial charges were calculated according to the standard AM1-BCC method and the dispersive (i.e., van der Waals) interactions (both intra-and intermolecular) were described by the sum of two-body Lennard-Jones contributions, with Amber force field parameters. ${ }^{49}$ Model potential molecular dynamics simulations were performed by using the NAMD 2.0 molecular simulations package. ${ }^{54}$ The equations of motion of atoms were integrated by using the Velocity Verlet algorithm with a time step as small as 1.0 fs. Multiple time stepping was used, with short-range nonbonded interactions calculated every two time steps and full electrostatics evaluated every four time steps. All the electrostatic contributions were computed by the Particle Mesh Ewald (PME) sum method, with grid spacing of $1 \AA$. Temperature was controlled by Langevin thermostat with damping coefficient of $1 \mathrm{ps}^{-1}$. Rigid bonds conditions were applied for the hydrogens and the atoms to which they are bonded. The VMD 1.9 molecular visualization program has been used to analyze the trajectories. ${ }^{55,56}$ The PTB7 bulk consists of 20 regioregular PTB7 chains of length $\approx 12 \mathrm{~nm}$ and periodically replicated along the backbone to mimic an infinite chain. Equilibration at room temperature and pressure was obtained by annealing using the Langevin thermostat and barostat (constant pressure constant temperature NPT ensemble) with anisotropic cell fluctuations for $1 \mathrm{~ns}$. The fullerene bulks were composed by 32 molecules and built accordingly to the conformation described in Casalegno et al. for both species, and relaxed with the same procedure used for PTB7. ${ }^{77-59}$ The cohesive energy density (CED) has been calculated by subtracting the energy of the isolated molecules from those of the relaxed systems and dividing by the equilibrated volume. 


\section{RESULTS AND DISCUSSION}

\subsection{Comparison DIO-free and DIO processed solar cells}

We first investigated solar cells prepared with $\mathrm{PTB} 7$ as electron donor mixed with $\mathrm{PC}_{71} \mathrm{BM}$ as electron acceptor at the $\mathrm{PTB} 7: \mathrm{PC}_{71} \mathrm{BM}$ weight ratio of 1:1.5 using either $\mathrm{DIO}$ as solvent additive or pure chlorobenzene solution. A schematic of the device structure explored is shown in Figure 1b. The current density-voltage (J-V) curves under solar illumination and the corresponding external quantum efficiency (EQE) spectra are displayed in Figure $2 a$ and $2 b$, respectively. DIO as a commonly used high boiling point additive significantly improves device performance as previously reported. ${ }^{13,42}$ Resulting photovoltaic parameters (power conversion efficiency PCE, open-circuit voltage $\mathrm{V}_{\mathrm{oc}}$, short-circuit density $\mathrm{J}_{\mathrm{sc}}$ and fill factor $\mathrm{FF}$ ) are higher for the DIOprocessed devices as highlighted in Table 1. PCE is more than doubled from 3.6\% to 8\%, which is caused by an increase in FF and $\mathrm{J}_{\mathrm{sc}}$. $\mathrm{EQE}$ values improve drastically with the addition of DIO to attain a maximum of $70 \%$ for the DIO-containing active layer. Nevertheless, the EQE spectra of both devices show a quasi-identical profile of photoconversion efficiency in the whole range from 300 to $800 \mathrm{~nm}$ corresponding to the resulting absorption of PTB7:PC ${ }_{71} \mathrm{BM}$ blend films (see Figure S1). This indicates that in both cases $\mathrm{PC}_{71} \mathrm{BM}$ and $\mathrm{PTB} 7$ contribute identically to the photocurrent generation. 
(a)

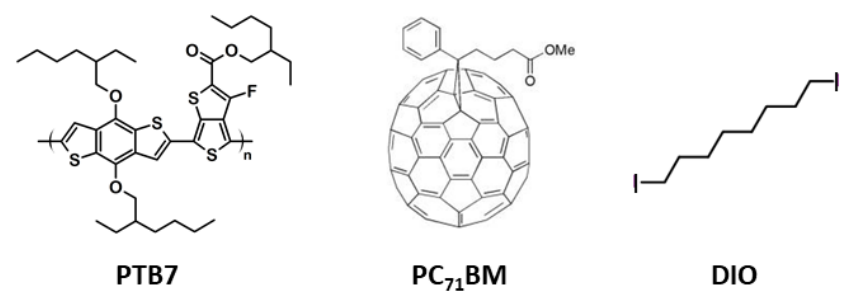

(b)

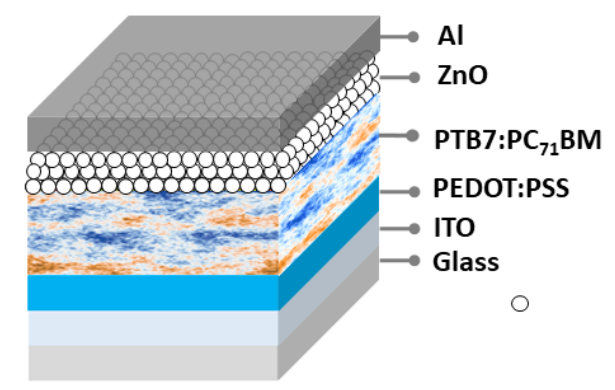

Figure 1. (a) Chemical structures of PTB7, $\mathrm{PC}_{71} \mathrm{BM}$ and $\mathrm{DIO}$ and (b) Schematic multi-layer device structure of bulk heterojunction solar cells.

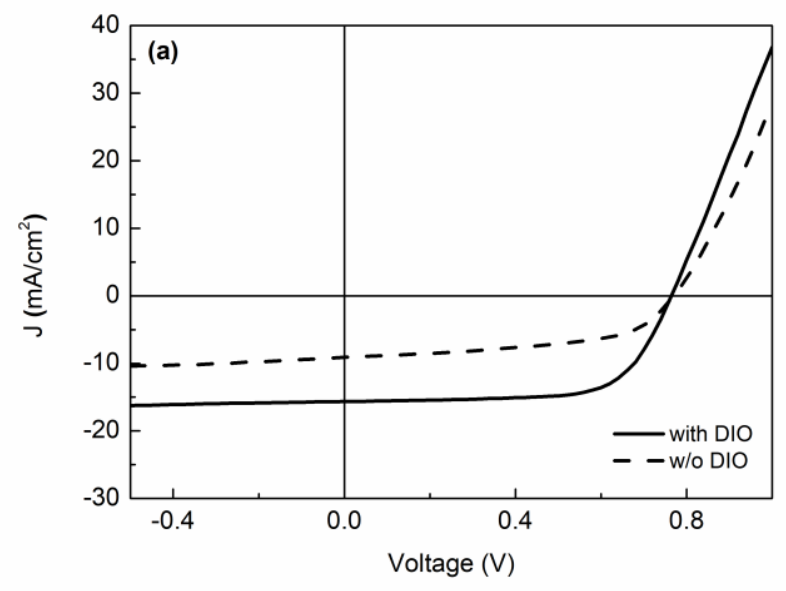




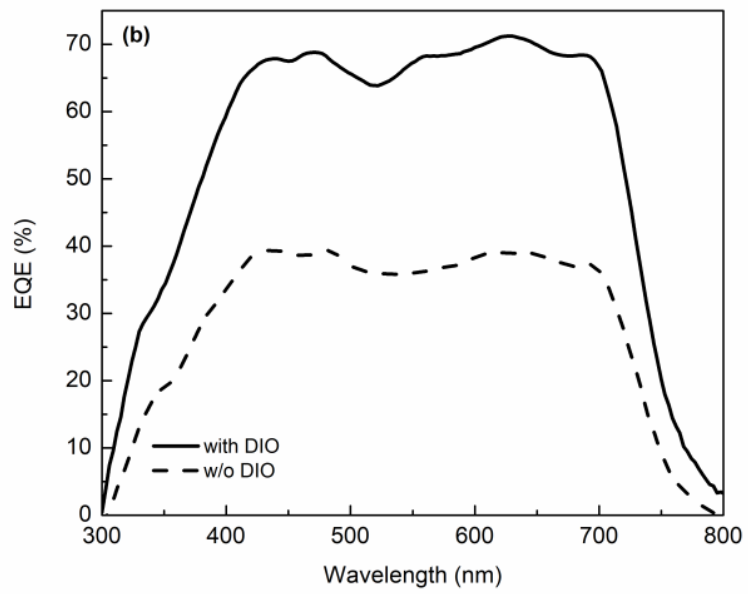

Figure 2. J-V curves (a) and EQE spectra (b) of PTB7:PC ${ }_{71} \mathrm{BM}$ solar cells (blend ratio 1:1.5) processed with and without DIO.

Table 1. Photovoltaic parameters (PCE, $\mathrm{V}_{\mathrm{oc}}, \mathrm{J}_{\mathrm{sc}}$ and $\mathrm{FF}$ ) of PTB7:PC $71 \mathrm{BM}$ bulk heterojunction solar cells as function of solvent additive DIO and blend ratio.

\begin{tabular}{|c|c|c|c|c|c|c|}
\hline & $\begin{array}{c}\text { PTB7:PC } 71 \mathrm{BM} \\
\text { ratio }\end{array}$ & $\begin{array}{c}\mathrm{PCE} \\
(\%)\end{array}$ & $\begin{array}{c}\mathrm{V}_{\mathrm{oc}} \\
(\mathrm{V})\end{array}$ & $\begin{array}{c}\mathrm{J}_{\mathrm{sc}} \\
\left(\mathrm{mA} / \mathrm{cm}^{2}\right)\end{array}$ & $\begin{array}{c}\mathrm{FF} \\
(\%)\end{array}$ & $\begin{array}{c}\text { average PCE } \\
( \pm \text { std dev. })\end{array}$ \\
\hline \multirow{3}{*}{ with DIO } & $1: 1.5$ & 8 & 0.764 & 15.64 & 67 & $7.89 \pm 0.09$ \\
\hline \multirow{3}{*}{ without DIO } & $1: 1.5$ & 3.6 & 0.77 & 9.05 & 52.3 & $3.44 \pm 0.11$ \\
\cline { 2 - 7 } & $1: 1$ & 3.6 & 0.78 & 9.37 & 49.4 & $3.39 \pm 0.13$ \\
\cline { 2 - 7 } & $1: 0.5$ & 2.95 & 0.80 & 8.23 & 44.9 & $2.75 \pm 0.18$ \\
\cline { 2 - 7 } & $1: 0.25$ & 1.86 & 0.735 & 7.05 & 36 & $1.65 \pm 0.14$ \\
\hline & $1: 0$ & 0.86 & 0.558 & 5.01 & 31 & $0.63 \pm 0.20$ \\
\hline
\end{tabular}

In Figure 3 we compare the out-of-plane and in-plane GIXD profiles of PTB7:PC 71 BM blend films at ratio 1:1.5 with and without DIO. The corresponding 2D-patterns as well as from pure donor and acceptor layers are provided in Figures S2 and S3, respectively. The profiles overlap nearly perfectly and reflect additive behavior of $\mathrm{PC}_{71} \mathrm{BM}$ and PTB7 peaks (Figure S4 and S5) for 
the parts corresponding to scattering angles superior to 5 deg. However, the peak in the range of small scattering angle (at 2.5-5 deg.) corresponding to the lamellar spacing of PTB7 polymer chains shifted in position to smaller angles when DIO was used indicating that the packing distance between lamellar polymer increased due to the addition of fullerenes in the polymer

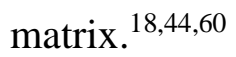

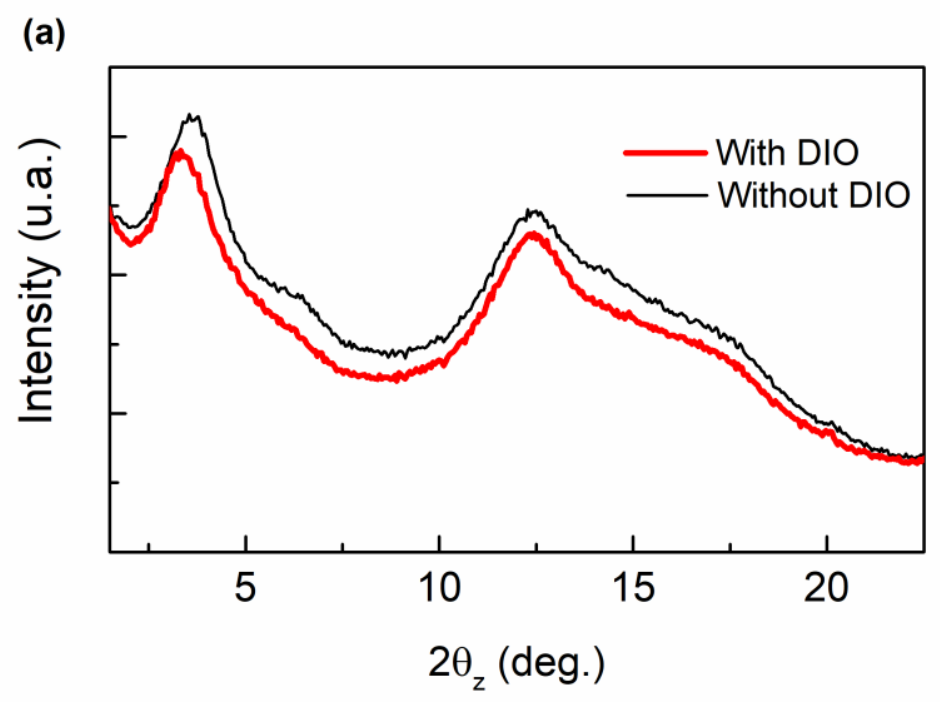

(b)

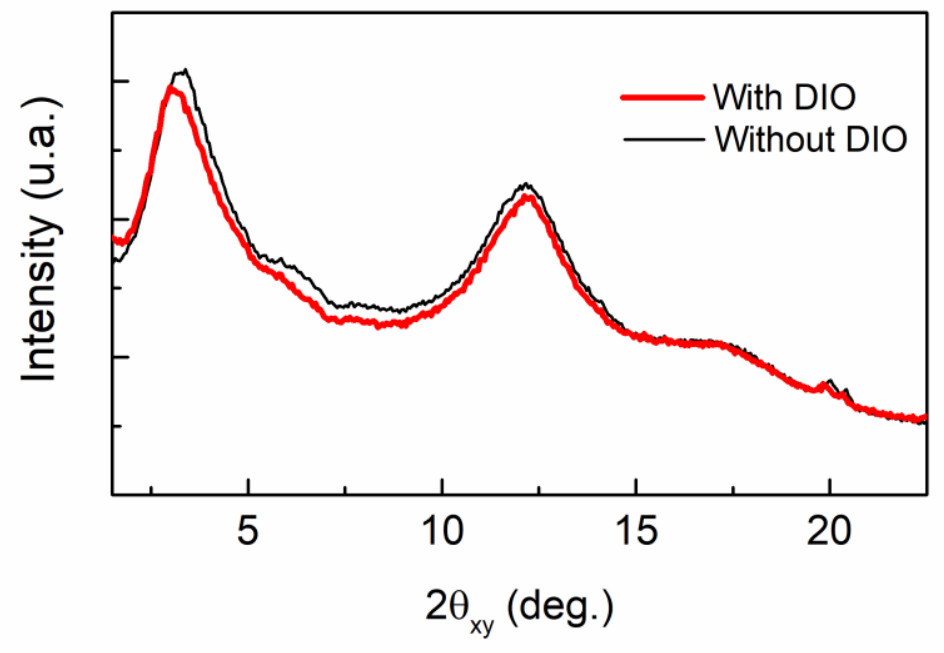

Figure 3. 2D-GIXD profiles of blend $\mathrm{PTB} 7: \mathrm{PC}_{71} \mathrm{BM}$ films (ratio1:1.5) processed with and without DIO: (a) out of plane (z) of line cut and (b) in plane (xy) of line cut. 
2D-GIXD does not provide information on local domain and interface distribution. Therefore we applied STEM-SI in the low-energy-loss range to visualize nanoscale textures in neat and DIOprocessed blends. The technique allows recording spatially resolved spectra of optical excitations and thereby enables distinguishing between donor and acceptor phases of blends similar to energy-filtered imaging series..$^{24,61}$ To create morphological maps, we used plasmon peak positions as mapped feature or machine learning on a spectral data set. The latter revealed minute non-linear effects between pure and mixed phases. ${ }^{25}$ However, to a first approximation spectral signals of mixed regions can be approximated by linear combinations of spectra from pure donor and acceptor layers. Here, we use signals from $\mathrm{PTB} 7$ and $\mathrm{PC}_{71} \mathrm{BM}$ pure layers (see Figure S6) to determine the spatial composition variations - and thereby also domain distributions - by multiple linear least-squares fitting to STEM-SI data sets of blends. In the fitting procedure the composite spectra from the blends are treated as linear combinations of the pure spectra. Mapping the determined coefficient for the fullerene spectrum in the linear combinations reveals the compositional distribution. In Figure 4, we compare conventional annular dark-field STEM images (Figures $4 \mathrm{a}$ and $4 \mathrm{~b}$ ) and maps of fullerene concentrations from fitting of STEM-STI data of neat and DIO-processed PTB7:PC ${ }_{71} \mathrm{BM}$ blend layers (Figures $4 \mathrm{c}$ and $4 \mathrm{~d}$ ). The nanoscale materials phases are identified as $\mathrm{PC}_{71} \mathrm{BM}$ rich domains in brown and $\mathrm{PTB} 7$ rich domains in blue together with the mixed phase in white. Comparing the morphologies of the DIO-processed blend with the blend processed without DIO reveals the expected differences with much finer details induced by additive use. ${ }^{29}$ As previously reported, DIO selectively dissolves $\mathrm{PC}_{71} \mathrm{BM}$ aggregates, thereby providing efficient intermixing between donor and acceptor molecules where $\mathrm{PC}_{71} \mathrm{BM}$ intercalates into PTB7 backbones optimizing both the domain size and the D:A 
interface. $^{62}$ Importantly, the compositional maps allow profiling of fullerene concentration. Figure $4 \mathrm{e}$ shows two averaged line profiles from the two given maps. For the D:A ratio of 1:1.5 and when using DIO, the domain sizes of both donor and acceptor enriched phases are small within a size range of $5-20 \mathrm{~nm}$, which conforms with exciton diffusion lengths. ${ }^{63-65}$ It is thus likely that excitons photogenerated inside PTB7 and $\mathrm{PC}_{71} \mathrm{BM}$ diffuse to the $\mathrm{D}$ : $\mathrm{A}$ interface, i.e. the mixed phase, which is present at high percentage (about $38 \%$ of phases as shown in a previous work $)^{29}$. In contrast, without additive large fullerene agglomerates form surrounded by polymer enriched phases, with domain sizes of $>100 \mathrm{~nm}$, which is significantly larger than exciton diffusion lengths. 

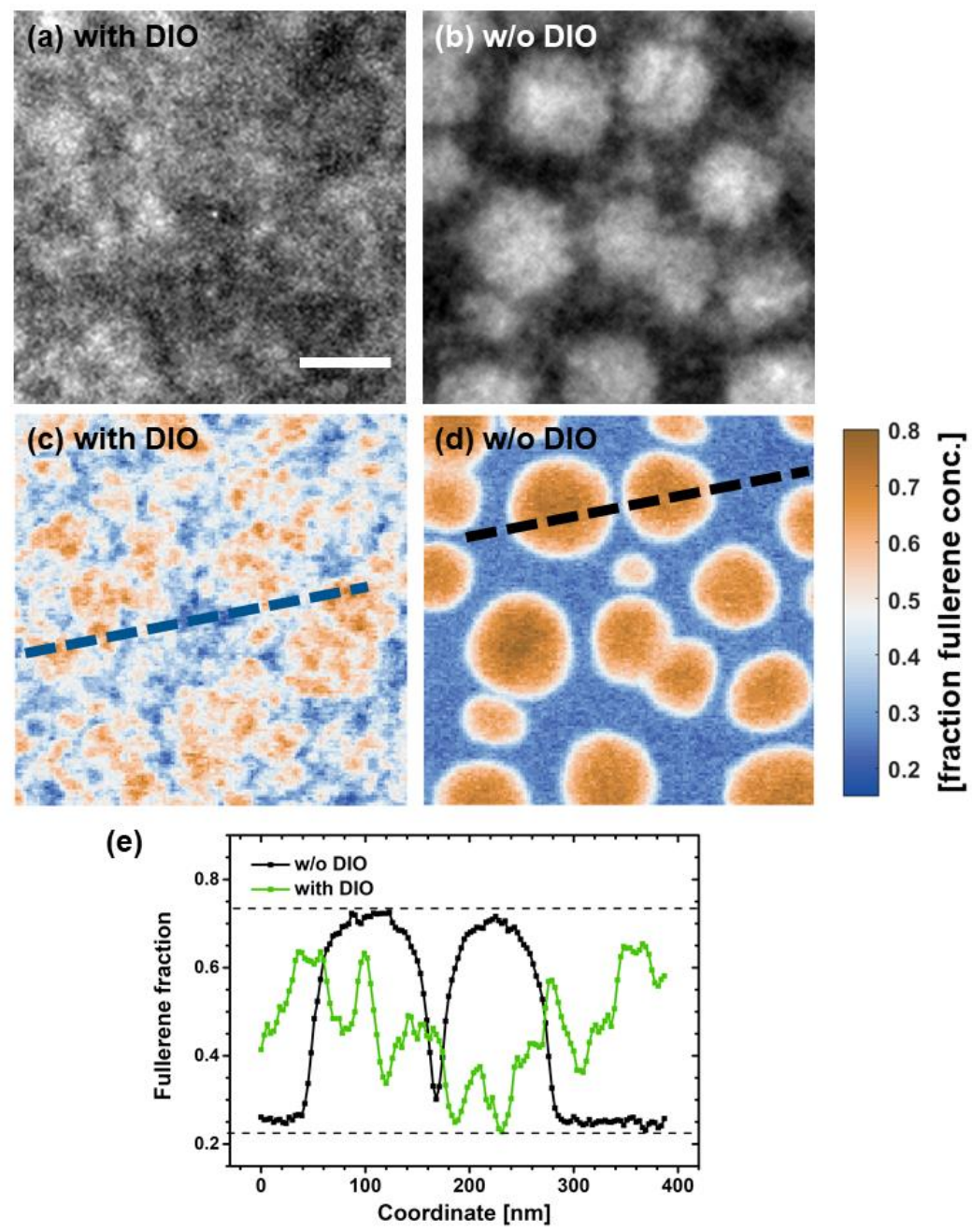

Figure 4. Annular dark-field STEM micrographs (a,b) and STEM-SI concentration maps of the fullerene fraction $(\mathrm{c}, \mathrm{d})$ of $\mathrm{PTB} 7: \mathrm{PC}_{71} \mathrm{BM}$ blends (ratio 1:1.5) processed with DIO (a,c) and without DIO $(b, d)$. The minimum value of the colourmap encoding the fullerene concentration ratio was set to 0.16 to highlight the fullerene concentration ratio of about 0.25 in the polymer enriched phase of the DIO free blend. Scale bar: $100 \mathrm{~nm}$. (e) Line profiles of fullerene fraction in STEM-SI maps.

Interestingly, the composition profiles for both layers show a minimum fullerene concentration of about $23 \%$. To show that this is not a result from overlapping domains and additive signal 
projection in the STEM experiment we generated dark-field and compositional maps of crosssectional views (Figure S7). DIO-processed blends show a uniform bulk distribution of the three coexisting phases ( $\mathrm{PC}_{71} \mathrm{BM}$ rich phase, the $\mathrm{PTB} 7$ rich and mixed phase). The thickness profile for the blend without DIO would show a continuous polymer enriched layer with $23 \%$ fullerene concentration. This implies that concentration variations around 23\% are not due to overlapping domains. The enriched PTB7 phase in direct contact with the mixed phase surrounding the acceptor domain acts as a continuous active layer sandwiched between the anode and the cathode. Simultaneously, the fullerene agglomerate concentration mapped in Figure $4 \mathrm{~d}$ can be a result of overlapping. The large fullerene agglomerate in Figure S7d is found on top of the small polymer-enriched layer. Hence, the maximum fullerene concentration in fullerene agglomerates must be larger than $73 \%$ as determined in projection through the layer (Figure $4 \mathrm{~d}-\mathrm{e}$ ). Although the device performance decreases when no DIO is used, a significant $\mathrm{J}_{\mathrm{sc}}$ is observed (see Figure 2a). Thus, the direct observation of the nanoscale morphology of DIO-free films shows that photocurrent generation may be a complex process in such layers, which are composed of large fullerene domains wrapped by the polymer-enriched phase. Indeed we can expect that the donor phase should actively contribute to the photocurrent generation, but it is an open question to what extent compared to the fullerene domains. The fullerene concentration in the PTB7 enriched phase has been determined to be about $25 \%$ (see Figure 4e) corresponding to the maximum miscibility of $\mathrm{PC}_{71} \mathrm{BM}$ in $\mathrm{PTB} 7$ as reported in the literature. ${ }^{29}$ This fullerene concentration may enable the formation of a bicontinuous network along the BHJ inside the donor phase. In order to answer these questions, we chose to characterize $\mathrm{PTB} 7: \mathrm{PC}_{71} \mathrm{BM}$ based solar cells with lower acceptor concentration to study blends only composed of a polymer enriched phase. 


\subsection{Photocurrent generation in polymer enriched blend solar cells}

We varied the mass ratio of $\mathrm{PTB} 7$ and $\mathrm{PC}_{71} \mathrm{BM}$ in the active layer using 1:1.5, 1:1, 1:0.5, and 1:0.25 and determined the fullerene concentration maps from spectroscopic imaging data sets. To show that the determined concentration maps and average concentration measures are valid using the spectral fitting procedure, we compared experimentally with theoretically expected values (Figure S8 and Table S1). Since the spectral composition is rather related to the number of molecules than the mass fraction in the layer, we converted the mass ratios to molecular ratios (see Experimental part and Table S1). Resulting D:A molecular ratios are 0.48:0.52, 0.58:0.42, 0.73:0.27, 0.85:0.15. We kept these numbers without scaling to highlight that for a mass ratio of 1:0.5, a molecular ratio of 0.73:0.27 is obtained, i.e. with $27 \%$ fullerenes a concentration where increased agglomeration should commence. In Figure S8 we provide experimentally determined molecular ratios as averages from three data sets for each of the four blends. Although at high fullerene concentration we observe an increasing underestimation of the fullerene content, the values are very close to the theoretical ones with a maximum deviation of $8 \%$. Figure 5 shows annular dark-field images (Figure 5a-e) and corresponding concentration maps (Figure 5f-j) for all indicated mass ratios. The pure polymer layer (Figure 5e and 5j) is shown as reference. From D:A ratio of 1:1.5 (Figures 5a and 5f) to 1:1 (Figures 5b and 5g), several morphological aspects of the layer change. The diameter of the fullerene domains decreases leading to an enlargement of their separation distance, i.e. an increase of the PTB7-enriched phase. For the ratio of 1:0.5 (Figures 5c and 5h), the large fullerene domains disappear to leave alone the polymer-enriched phase. However, the concentration map shows a color contrast in this phase of very small nanosized structures with fullerene concentration up to about 0.5. This implies that whereas the average fullerene concentration ratio in the layer is about 0.27 (see Table S1), small fullerene 
aggregates of a concentration ratio approaching 1 are embedded in the polymer matrix. A higher resolution map showing the variable concentrations or domains at the nanometer level is provided in Figure S9. Further decrease in fullerene concentration to a ratio of 1:0.25 (Figures 5d and 5i) leads to homogeneous layers in which the fullerene concentration is clearly reduced, and the nano-sized structures are not visible anymore. The concentration map resembles the map for the pure polymer layer. Nevertheless, the average molecular fullerene fraction for this sample is determined to be 0.15 . Due to the required large dynamic range, the colourmap cannot display the fine variations in this range of concentrations. By comparing the layers with high fullerene concentration in both top view as well as cross view (Figure S7) with the layer of ratio 1:0.5, we observe similar fullerene sub-structures in the polymer enriched domains for the 1:1 and 1:1.5 ratios (see Figures $5 \mathrm{f}$ and 5g). Only below 1:0.5, no sub-structures are observed in the polymer enriched phase. We note that here, very small agglomerations $<4 \mathrm{~nm}$ (the nominal resolution in Figure S9) might exist and indeed not be detected due to overlapping effects. The observation of sub-structures indicates that fullerenes are not homogenously distributed inside the polymer but reorganized into clusters of local concentrations larger than $23-27 \%$, i.e. clearly more than the maximum miscibility of $\mathrm{PC}_{71} \mathrm{BM}$ in $\mathrm{PTB} 7$, surrounded by polymer domains with local concentrations of less than 23\% (see Figure S9). 

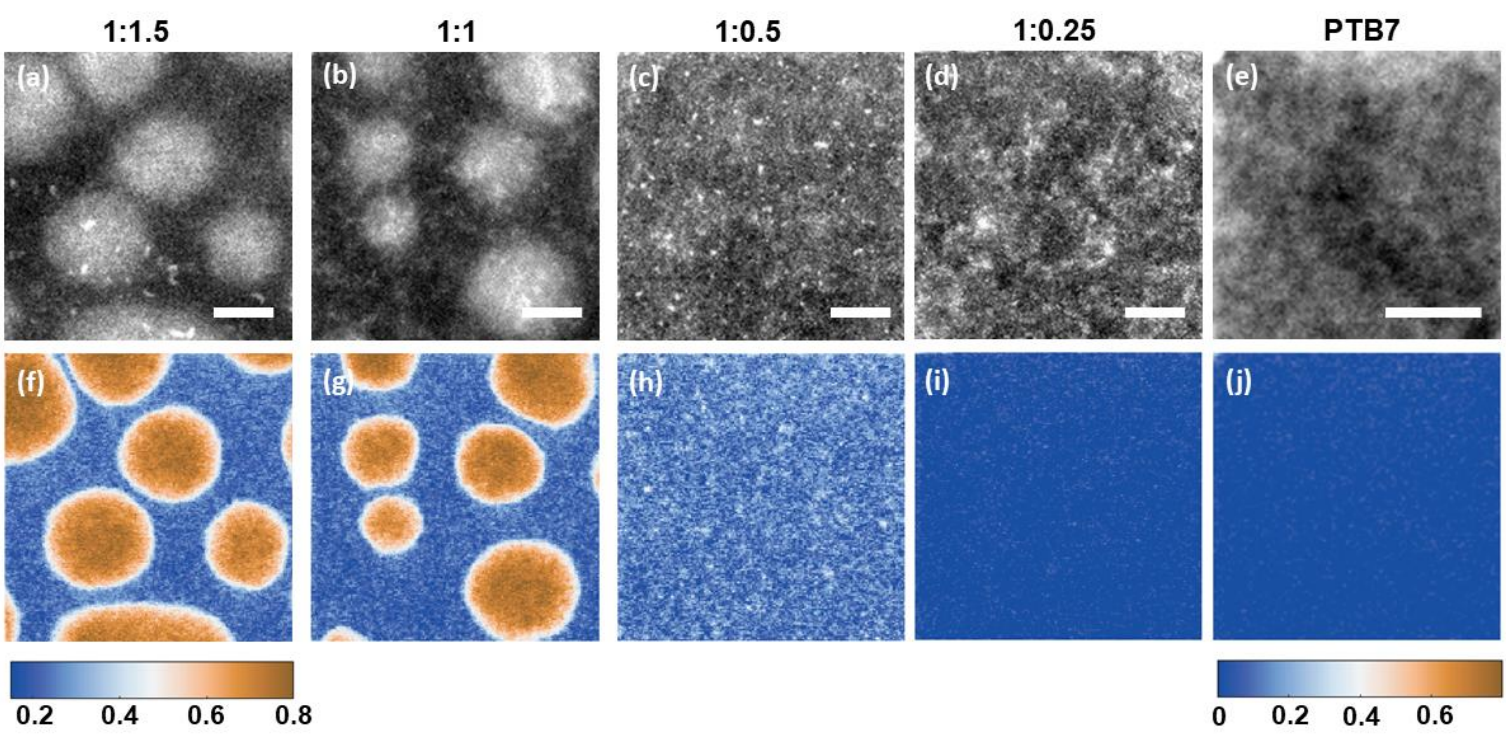

[fraction fullerene conc.]

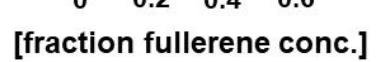

Figure 5. Annular dark-field STEM micrographs (a-e) and STEM-SI concentration maps of fullerene fractions (f-j) of $\mathrm{PTB} 7: \mathrm{PC}_{71} \mathrm{BM}$ blends processed without $\mathrm{DIO}$ as blend ratio: ratio 1:1.5 (a, f), 1:1 (b, g), 1:0.5 (c, h) and 1:0.25 (d, i) while 1:0 corresponds to PTB7 (e,j). Scale bar: $100 \mathrm{~nm}$.

The J-V characteristic curves and EQE spectra of the solar cells processed with the corresponding blends are shown in Figure $6 \mathrm{a}$ and $6 \mathrm{~b}$, respectively. The photovoltaic performances are summarized according to the $\mathrm{J}-\mathrm{V}$ curves and listed in Table 1. With a FF comparable to the pure PTB7 device (31-36\%), the D:A weight ratio 1:0.25 suffers mainly from the small amount of fullerene where a low average PCE value of $1.65 \%$ is obtained. With comparable $\mathrm{J}_{\mathrm{sc}}\left(8.23-9.08 \mathrm{~mA} / \mathrm{cm}^{2}\right)$ and $\mathrm{FF}(45-52 \%)$, the $\mathrm{D}: \mathrm{A}$ weight ratios $1: 1.5$ to $1: 0.5$ suggest a charge generation that is with low dependence of D:A ratio. Furthermore, PCE is decreased by less than $20 \%$ when the ratio is reduced from $1: 1.5$ to $1: 0.5$. 

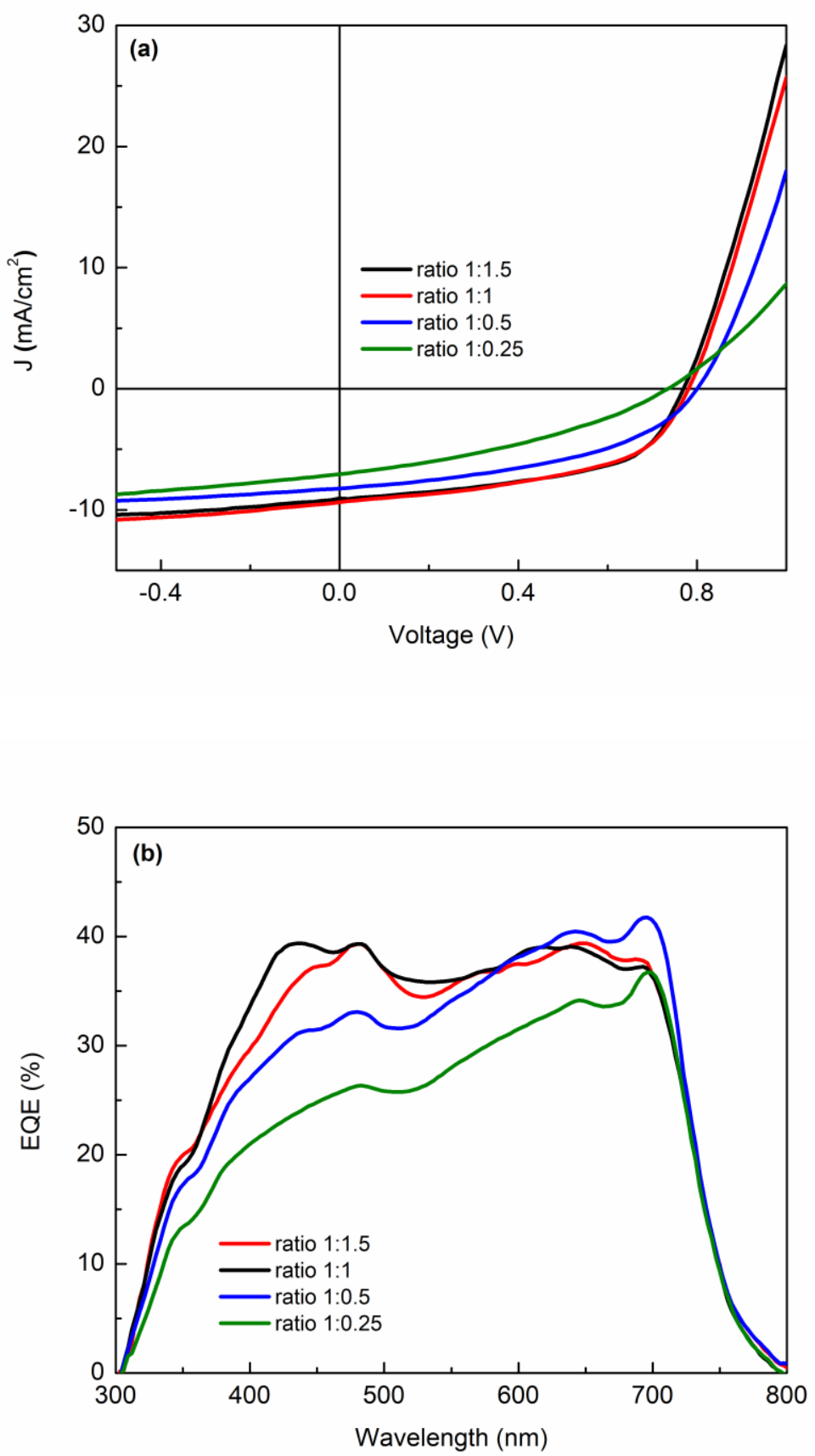

Figure 6. J-V curves (a) and EQE spectra (b) of PTB7:PC 71 BM solar cells processed without DIO and with blend ratio 1:0.25, 1:0.5, 1:1 and 1:1.5. 
By using the equation (eq 2), thus neglecting recombination:

$G=\frac{J}{e d}$

where $J$ is the measured current density under reverse bias $(-0.5 \mathrm{~V}), e$ is the elementary charge and $d$ the thickness of thin films, the generation rates are calculated as $0.6-0.74 \times 10^{28} \mathrm{~m}^{-3} \mathrm{~s}^{-1}$ for the DIO-free processed active layers of ratio 1:1.5 and 1:0.5, respectively. ${ }^{41}$ The comparable generation rate implies the same D:A interface for exciton splitting and thus identify the polymer enriched phase with the fullerene sub-structure to be strongly involved in the photocurrent generation. Taking into account the EQE spectra (Figure 6b) both polymer and fullerene contribute equally to the photocurrent generation independently of ratio 1:1.5, 1:1: and 1:0.5 with only a small decrease in the range of $400-550 \mathrm{~nm}$ related to the reduction of the fullerene concentration and thus absorption. Regarding the $\mathrm{J}-\mathrm{V}$ characteristics for the 1:0.5 ratio together with the nanoscale morphology visualization (Figure 5h), we can thus clearly say that a large part of the photocurrent density can be generated in polymer enriched phase with values of more than $60 \%$ of the $\mathrm{J}_{\mathrm{sc}}$ obtained in DIO-processed and optimized solar cells. Moreover, our observations show that the interface of exciton dissociation does not solely occur at the interface between the large donor and polymer enriched domains, which are present with ratios 1:1.5 and 1:1. Excitons are thus dissociated throughout the donor enriched phase at the interface with the fullerene substructures while electrons are likely to be transported across sub-structures towards the fullerene enriched domains.

To understand the mechanism of the photocurrent transport inside polymer enriched phase containing the fullerene sub-structure, 2D-GIXD measurements can be analyzed with respect to the incorporation of the fullerenes inside the polymer. The predominant composition of PTB7 is 
confirmed by 2D-GIXD on DIO-free processed PTB7:PC 71 BM active layer systems (see Figure S5) where the intensities of the PTB7 reflections are highly underlined in the profile of D:A layer at 1:0.5 with a main peak at $2 \Theta_{\mathrm{z}}$ of $14.8 \mathrm{deg}$. Nevertheless, the incorporation of fullerene in the polymer network is also highlighted by the presence of shoulders at $2 \Theta_{z}$ of 12.5 and $17.7 \mathrm{deg}$. corresponding to the peak of bare $\mathrm{PC}_{71} \mathrm{BM}$. This proofs that the nano-sized structures in Figure $5 \mathrm{~h}$ correspond to the small $\mathrm{PC}_{71} \mathrm{BM}$ domains with a crystalline organization making charge transport efficient between the fullerenes. It was shown for DIO-processed PTB7:PC $71 \mathrm{BM}$ active layer systems, reported by Ho et al., that fullerene domains should act as small nanoparticles responsible of the electron conduction once the fullerene concentration reaches the percolation threshold of more than 1:0.3. ${ }^{44}$ To evaluate the impact of the formation of the fullerene substructures in the case of DIO-free processed layers, we determined the charge transport properties of the blend films with different D:A weight ratio. To this end we used the SCLC protocol described by Blakesley et al. ${ }^{48}$ extracting the mobility from I-V curves of hole-only devices and electron-only devices. I-V curves were fitted using equation (1) in the SCLC region considering a field-dependence of the mobility. Hole $\left(\mu_{\mathrm{h}}\right)$ and electron $\left(\mu_{\mathrm{e}}\right)$ mobility values obtained for $\mathrm{PTB} 7: \mathrm{PC}_{71} \mathrm{BM}$ BHJ layers without $\mathrm{DIO}$ as function of blend ratio are summarized in Table 2. A complete worked example and the corresponding data fitting is given in SI together with the values of thicknesses in Table S2. Figure 7 shows representative dark current and fitting curves for each blend ratio. Based on hole-only devices, the hole mobility is not reduced by blending with $\mathrm{PC}_{71} \mathrm{BM}$ with a value consistent with the hole mobility of neat PTB7 obtained previously by SCLC. ${ }^{13,44,66-68}$ In contrast, the electron mobility in PTB7:PC 71 BM blends is largely impacted as function of $\mathrm{PC}_{71} \mathrm{BM}$ content. For both $1: 1.5$ and 1:1, the electron mobility reaches the saturated values of $1-6 \times 10^{-4} \mathrm{~cm}^{2} / \mathrm{Vs}$ to be consistent with the reported values. ${ }^{44}$ Well 
balanced electron and hole mobilities were obtained at 1:1.5 and 1:1 ratio, together with higher PCE and FF restricting the build-up of space charges, and hence, reducing charge recombination. At the D:A ratio of 1:0.5, the electron mobility decreases but does not completely diminish with values of $3.8-8.6 \times 10^{-6} \mathrm{~cm}^{2} / \mathrm{Vs}$, which are close to mobilities observed in DIO processed blends at identical ratio. This indicates that the electron transport pathway persists in percolation through the crystalline small domains observed in thin films by STEM-SI and 2D-GIXD.
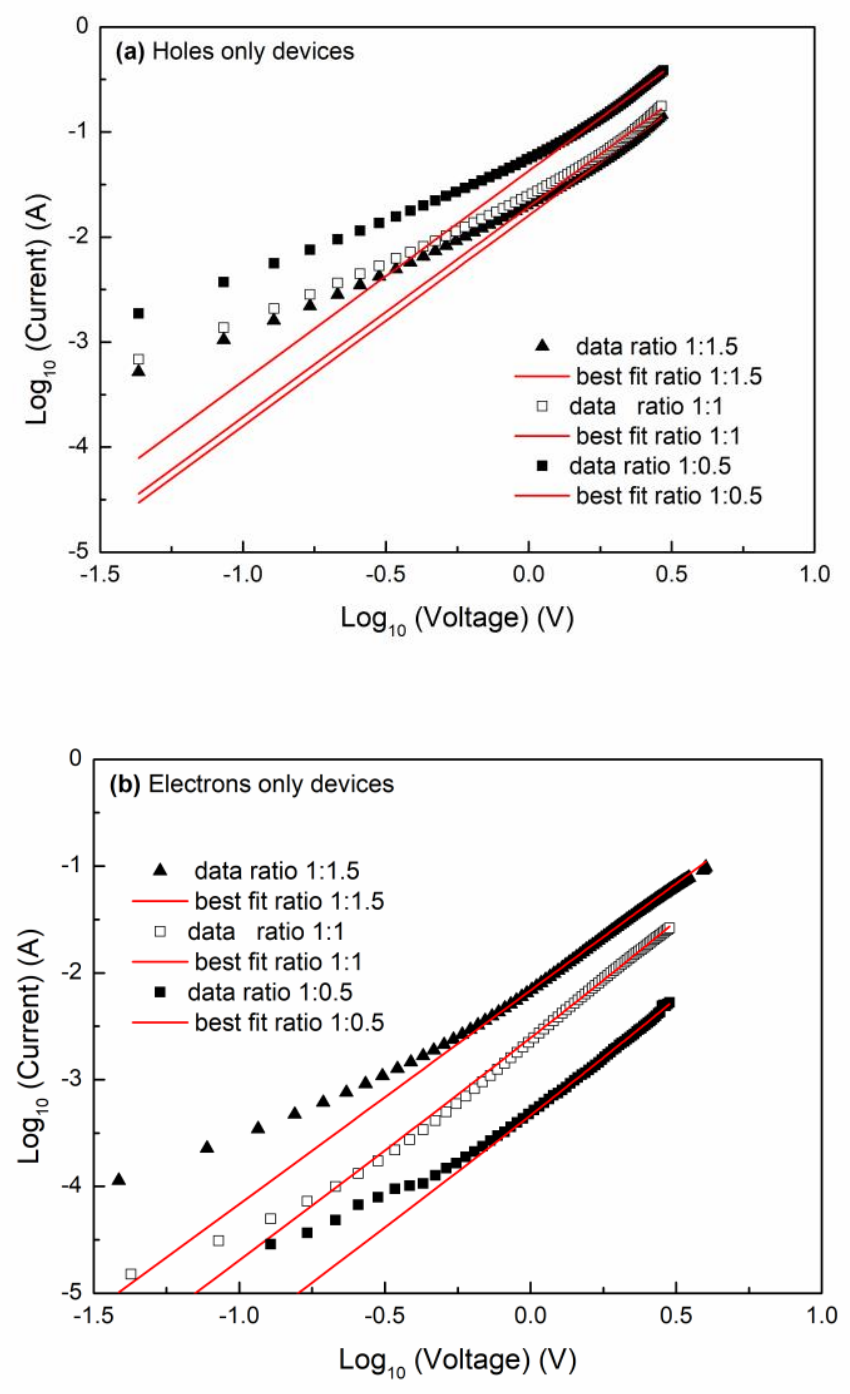
Figure 7. Current vs voltage for holes (a) and electron (b) only devices. The charges carrier mobilities of PTB7:PC $71 \mathrm{BM}$ blends were determined following the single-carrier devices SCLC model.

Table 2. Hole $\left(\mu_{\mathrm{h}}\right)$ and electron $\left(\mu_{\mathrm{e}}\right)$ mobility values obtained by SCLC of PTB7:PC 71 BM bulk heterojunction layers without DIO as function of blend ratio.

\begin{tabular}{|c|c|c|c|c|}
\hline $\begin{array}{c}\text { PTB7:PC } \\
\text { ratio }\end{array}$ & Film & $\begin{array}{c}\text { Average } \\
\text { thickness } \\
\mathrm{d}(\mathrm{nm})\end{array}$ & $\mu_{\mathrm{h}}\left(\mathrm{cm}^{2} / \mathrm{V} . \mathrm{s}\right)$ & $\mu_{\mathrm{e}}\left(\mathrm{cm}^{2} / \mathrm{V} . \mathrm{s}\right)$ \\
\hline \multirow{2}{*}{$1: 1.5$} & $\mathrm{~A}$ & 73 & $3.9-4.3 \times 10^{-4}$ & $5.88-6.15 \times 10^{-4}$ \\
\cline { 2 - 5 } & $\mathrm{B}$ & 111 & $6.4-7.3 \times 10^{-4}$ & $2.75-3.1 \times 10^{-4}$ \\
\hline \multirow{2}{*}{$1: 1$} & $\mathrm{C}$ & 80 & $3.05-3.4 \times 10^{-4}$ & $2.32-2.68 \times 10^{-4}$ \\
\hline \multirow{2}{*}{$1: 0.5$} & $\mathrm{D}$ & 119 & $0.97-1.23 \times 10^{-3}$ & $0.95-1.15 \times 10^{-4}$ \\
\cline { 2 - 5 } & $\mathrm{E}$ & 50 & $7.23-7.77 \times 10^{-4}$ & $3.86-5.45 \times 10^{-6}$ \\
\hline & $\mathrm{F}$ & 90 & $9.65-9.95 \times 10^{-4}$ & $7.74-8.66 \times 10^{-6}$ \\
\hline
\end{tabular}

To understand fullerene aggregation and charge transport in the polymer phase, molecular dynamics simulations were adopted to estimate the enthalpy of mixing of the polymer:fullerene blends without $\mathrm{DIO} .{ }^{29} \mathrm{We}$ previously reported that $50 \%$ of $\mathrm{PC}_{71} \mathrm{BM}$ content generates a highly stable phase in which the blend and the separate phases have similar enthalpy values and thus no driving force for phase separation exists. The low mixing enthalpy derives from the high fullerene-PTB7 interaction that leads to densely packed regions of fullerene molecules (hereafter referred to as clusters) intercalated within the polymer. Figure 8a shows the fullerene organization inside the blend with 1:0.5, 1:1 and 1:1.5 weight ratio. We find that the fullerenes form clusters inside the polymer blend. The fullerene-fullerene distance within the clusters is less than $\sim 1.5 \AA$. By decreasing the fullerene concentration from ratio of $1: 1.5$ down to $1: 05$, the size of the clusters decreases while their relative distance increases (see Figure 8a). In general, the 
key property for the electron transport in the blend is the distance between fullerenes. The electron hopping is efficient when the fullerene-fullerene distance (defined as the distance between fullerenes surfaces) is comparable to the value of the crystalline $\mathrm{PC}_{71} \mathrm{BM}$ phase, i.e. $\sim 1.5 \AA$ As the distance between clusters increases, the hopping probability decreases. Accordingly, the bottleneck for electron mobility of the blends is the average distance $\bar{d}$ between clusters. A cluster is here defined as a group of fullerenes which are separated by less than $\sim 1.5$ $\AA$. The calculated distance $\bar{d}(x)$ increases when the fullerene concentration, $1: x$, decreases and we find values $4.27 \AA$, $5.89 \AA$ and $7.76 \AA$ for fullerene concentrations $x$ equal to $1.5,1$ and 0.5 , respectively. In order to compare our results with the experimental mobilities, we assume that the electron mobility $\mu_{e}$ decreases exponentially with cluster distance, i.e. $\mu_{e}(x) \sim C e^{-\bar{d}(x) / \delta}$, where $C$ is unknown constant and $\delta=1.5 \AA$. By using the values $\bar{d}(x)$ calculated in the atomistic models above it is possible to fit $C$ to reproduce the experimental mobilities of Table 2 (see Figure 8b). Error bars are taken as the difference between the mobilities at the same polymer:fullerene weight ratio. At $\bar{d}=1.5 \AA$, corresponding to the average distance between fullerenes in the bulk, we estimate a mobility of $\mu_{e}=2.85 \times 10^{-3} \mathrm{~cm}^{2} / \mathrm{Vs}$, which is in the order of the experimental mobilities of neat $\mathrm{PC}_{71} \mathrm{BM}$ films. ${ }^{13,44,69}$ Our theoretical analysis shows that fullerenes are not homogenously distributed inside the PTB7 but tend to form elongated clusters along the backbone of the polymer chains driven by the mixing enthalpy of the $\mathrm{PTB} 7: \mathrm{PC}_{71} \mathrm{BM}$ blend. The average distance between theses nano-sized fullerene clusters governs the electron mobility. The nano-sized fullerene clusters give rise to a network inside the polymer that favors electron transport towards the fullerene-enriched domains. 
(a)
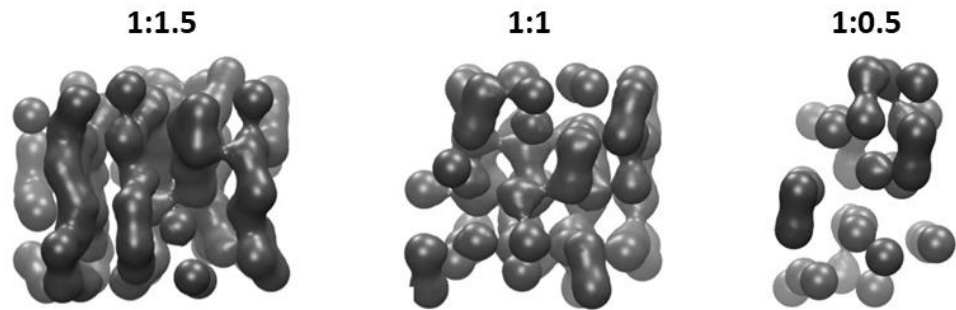

(b)

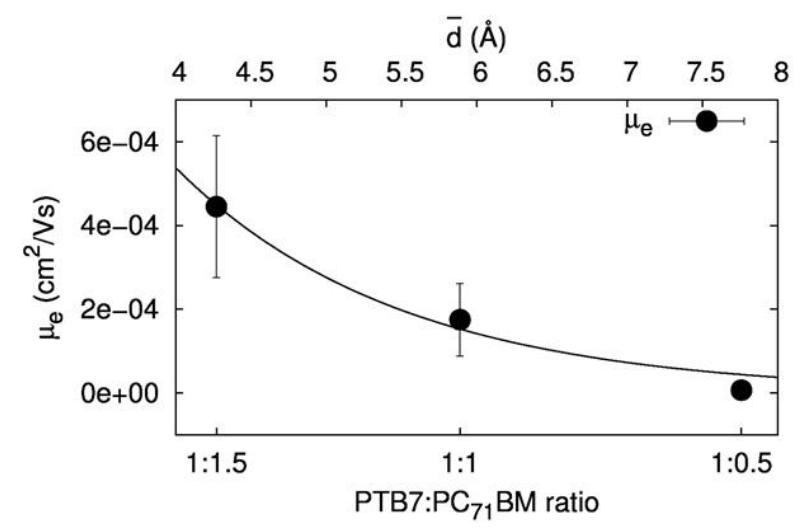

Figure 8. (a) Calculated $\mathrm{PTB} 7: \mathrm{PC}_{71} \mathrm{BM}$ blend morphology as function of fullerene $\mathrm{w} \%$ inside the polymer blend (shown on top of each panel). Only $\mathrm{PC}_{71} \mathrm{BM}$ is shown for clarity. The models are built with identical amount of polymer and different fullerene concentrations. Grey isosurfaces are obtained from a volumetric Gaussian density map (each fullerene is taken as single particle with coordinates equal to its center of mass) with radius scale equal to the average fullerene radius (i.e. $\sim 3.7 \AA$ ), density isovalue equal to $0.5 \AA$, and grid spacing equal to $1 \AA .55,58$ (b) Experimental mobilities fitted by the model $\mu_{e}(x) \sim C e^{-\bar{d}(x) / \delta}$, with $\delta=1.5 \AA$. We obtain $C$ $=7.74 \times 10^{-3} \mathrm{~cm}^{2} / \mathrm{Vs}$.

\section{CONCLUSION}

Visualizing and analyzing the inner domain size distribution and absolute domain composition of fullerene-based polymer blend films is highly essential to correlate the morphology and the photocurrent generation. Here we studied $\mathrm{PTB} 7: \mathrm{PC}_{71} \mathrm{BM}$ blend films processed without additive 
via varying the ratio of $\mathrm{PTB} 7$ and $\mathrm{PC}_{71} \mathrm{BM}$ in the active layer so that non-optimized blends were created containing large fullerene domains or a single polymer enriched phase. Our results show that fullerenes are not homogeneously distributed in the polymer phase but form clusters that, at the higher fullerene concentrations, tend to form fullerene networks inside the donor phase. Molecular dynamics simulations of the polymer-fullerene blends point towards the mixing enthalpy of the $\mathrm{PTB} 7: \mathrm{PC}_{71} \mathrm{BM}$ mixture as driving force for the cluster formation. The formation of the fullerene network not only reduce the concentration of electron trap states but also promote efficient electron transport paths inside the PTB7 phases via electron hopping processes.

The formation of the fullerene clusters is governed by the mixing enthalpy of the PTB7:PC ${ }_{71} \mathrm{BM}$ blend and depends thus on the chemical structure of both donor and acceptor materials. Our future work will focus on the deeper understanding on the polymer:acceptor interaction so that a voluntarily generation of an acceptor sub-networks in the polymer enriched domains is possible by suitable design of non-fullerene acceptor. This can lead to enhanced electron extraction and thus higher processing tolerance of high efficiency blends against formation of morphological defects such as large polymer enriched domains surpassing the exciton diffusion lengths.

\section{ASSOCIATED CONTENT}

\section{Supporting information}

The supporting information is available free of charge on the ACS Publication website at DOI:xxx.

Absorption spectra of PTB7, $\mathrm{PC}_{71} \mathrm{BM}$ and a 1:1.5 blend films. 2D-GIXD patterns. 2D-GIXD profiles (out of plane and in plane) of bare $\mathrm{PTB} 7, \mathrm{PC}_{71} \mathrm{BM}$ and $\mathrm{PTB} 7: \mathrm{PC}_{71} \mathrm{BM}$ blends. Electron energy-loss spectra of pure PTB7 and PC71BM. Annular dark-field images and fullerene concentration maps using STEM-SI of the cross-sectional preparations of PTB7:PC ${ }_{71} \mathrm{BM}$ blends (ratio 1:1.5) processed with DIO and without DIO. Experimental average molecular fullerene fractions in $\mathrm{PTB} 7: \mathrm{PC}_{71} \mathrm{BM}$ blends of ratios 1:0.25, 1:0.5, 1:1, and 1:1.5 in comparison to expected molecular fractions. High resolution annular dark-field image and fullerene concentration map using STEM-SI of a $\mathrm{PTB} 7: \mathrm{PC}_{71} \mathrm{BM}$ blend (ratio 1:0.5) processed without 
DIO. Thickness values obtained by profilometry of PTB7:PC ${ }_{71} \mathrm{BM}$ bulk heterojunction layers. Analysis of experimental mobilities by SCLC.

\section{AUTHOR INFORMATION}

Corresponding Authors

* E-mail: m.pfannmoeller@uni-heidelberg.de (Martin Pfannmöller)

* E-mail: videlot@ cinam.univ-mrs.fr (Christine Videlot-Ackermann)

\section{ORCID}

Sadok Ben Dkhil: 0000-0002-8035-7581

Pavlo Perkhun: 00oo-0001-7458-3411

Sara Bals: 000o-0002-4249-8017

Daiki Kuzuhara: oooo-0001-7948-8501

Stephan Thierry Dubas: 0000-0002-7188-3096

Claudia Caddeo: 00oo-0002-1090-9897

Alessandro Mattoni: oooo-0002-1381-6557

Olivier Margeat: 0000-0003-3716-2399

Uli Würfel: oooo-0003-4151-8538

Jörg Ackermann: 0ooo-0003-2586-3788

Martin Pfannmöller: 00oo-0002-0910-1591

Christine Videlot-Ackermann: 0000-0001-8240-6474

\section{Present Addresses}

$\left[{ }^{\S}\right]$ Present address: Dracula Technologies, 4 Rue Georges Auric, 26000 Valence, France.

$\left[{ }^{\#}\right]$ Present address: Centre for Advanced Materials, Heidelberg University, 69120 Heidelberg, Germany.

\section{Author Contributions}

The manuscript was written through contributions of all authors. All authors have given approval to the final version of the manuscript.

\section{Notes}

The authors declare no competing financial interest.

\section{ACKNOWLEDGMENTS}

JA, OM and CVA acknowledge financial support by the French Fond Unique Interministériel (FUI) under the project "SFUMATO" (Grant number: F1110019V/201308815) as well as by the European Commission under the Project "SUNFLOWER" (FP7-ICT-2011-7, Grant number: 
287594). JA, CVA and EB acknowledge the ANRT (Association Nationale de la Recherche et de la Technologie) and the Ministère de l'Enseignement Supérieur, de la Recherche et de l'Innovation, awarded through the company Dracula Technologies (Valence, France) for framework of a CIFRE PhD grant 2017/0529. JA and PP received funding from the European Union's Horizon 2020 research and innovation program under the Marie Skłodowska-Curie Grant Agreement No. 713750. They further acknowledge support of the Regional Council of Provence-Alpes-Côte d'Azur, A*MIDEX (No. ANR-11-IDEX-0001-02), and the Investissements d'Avenir project funded by the French Government, managed by the French National Research Agency (ANR). JA and YAAQ acknowledge the French Research Agency for funding through the project NFA-15 (ANR-17-CE05-0020-01). NY acknowledges the synchrotron radiation experiments were performed at BL19B2 in SPring-8 with the approval of Japan Synchrotron Radiation Research Institute (JASRI) (Proposal Nos. 2017B1629 and 2018B1791). SB acknowledges financial support from the European Research Council (ERC Consolidator Grant \# 815128 -REALNANO) and from FWO (G.0381.16N). AM acknowledges Italian MIUR for funding through the project PON04a2 00490 M2M Netergit, PRACE for awarding access to Marconi KNL at CINECA, Italy, through projects DECONVOLVES (2018184466) and PROVING-IL (2019204911). MP gratefully acknowledges funding by the Ministerium für Wissenschaft, Forschung und Kunst Baden-Württemberg through the HEiKA materials research centre FunTECH-3D (MWK, 33-753-30-20/3/3) and the Large-Scale-Data-

Facility (LSDF) sds@hd through grant INST 35/1314-1 FUGG. CC acknowledges the CINECA award under the ISCRA initiative, for the availability of high performance computing resources and support (project MITOMASC).

\section{REFERENCES}

(1) Li, G.; Zhu, R.; Yang, Y. Polymer Solar Cells. Nat. Photonics 2012, 6, 153-161.

(2) Li, H.; Xiao, Z.; Ding, L.; Wang, J. Thermostable Single-Junction Organic Solar Cells with a Power Conversion Efficiency of 14.62\%. Sci. Bull. 2018, 63, 340-342.

(3) Inganäs, O. Organic Photovoltaics Over Three Decades. Adv. Mater. 2018, 30, 1800388.

(4) Wadsworth, A.; Moser M.; Marks A.; Little M.S.; Gasparini N.; Brabec C.J.; Baran D.; McCulloch I. Critical Review of the Molecular Design Progress in Non-Fullerene Electron 
Acceptors Towards Commercially Viable Organic Solar Cells. Chem. Soc. Rev. 2018, 48, 15961625.

(5) Liu Q.; Jiang Y.; Jin K.; Qin J.; Xu J.; Li W.; Xiong J.; Liu J.; Xiao Z.; Sun K.; Yang S.; Zhang X.; Ding L. 18\% Efficiency Organic Solar Cells, Science Bulletin 2020, 65, 272-275.

(6) Cui, Y. Yao H.; Hong L.; Zhang T.; Xu Y.; Xian K.; Gao B.; Qin J.; Zhang J.; Wei Z.; Hou J. Achieving Over 15\% Efficiency in Organic Photovoltaic Cells via Copolymer Design. Adv. Mater. 2019, 31, 1808356.

(7) Cui, Y.; Yao, H.; Zhang, J.; Zhang T.; Wang Y.; Hong L.; Xian K.; Xu B.; Zhang S.; Peng J.; Wei Z.; Gao F.; Hou J. Over 16\% Efficiency Organic Photovoltaic Cells Enabled by a Chlorinated Acceptor with Increased Open-Circuit Voltages. Nat. Commun. 2019, 10, 2515.

(8) Ye L.; Hu H.; Ghasemi M.; Wang T.; Collins BA.; Kim J.H.; Jiang K.; Carpenter J.H.; Li H.; Li Z.; McAfee T.; Zhao J.; Chen X.; Lai J.L.Y.; Ma T.; Brédas J.L.; Yan H.; Ade H. Quantitative Relations between Interaction Parameter, Miscibility and Function in Organic Solar Cells. Nat. Mater. 2018, 17, 253-260.

(9) Fan, B.; Du X.; Liu F.; Zhong W.; Ying L.; Xie R.; Tang X.; An K.; Xin J.; Li N.; Ma W.; Brabec C.J.; Huang F.; Cao Y. Fine-Tuning of the Chemical Structure of Photoactive Materials for Highly Efficient Organic Photovoltaics. Nat. Energy 2018, 3, 1051-1058.

(10) Menke, S. M., Ran, N. A., Bazan, G. C., Friend, R. H. Understanding Energy Loss in Organic Solar Cells: Toward a New Efficiency Regime. Joule 2018, 2, 25-35.

(11) Zhou, Z. Xu S.; Song J.; Jin Y.; Yue Q.; Qian Y.; Liu F.; Zhang F.; Zhu X. HighEfficiency Small-Molecule Ternary Solar Cells with a Hierarchical Morphology Enabled by Synergizing Fullerene and Non-Fullerene Acceptors. Nat. Energy 2018, 3, 952-959.

(12) Gao K.; Jo S.B.; Shi X.; Nian L.; Zhang M.; Kan Y.; Lin F.; Kan B.; Xu B.; Rong Q.; Shui L.; Liu F.; Peng X.; Zhou G.; Cao Y.; Jen A. K.-Y. Over 12\% Efficiency Nonfullerene AllSmall-Molecule Organic Solar Cells with Sequentially Evolved Multilength Scale Morphologies. Adv. Mater. 2019, 31, 1807842.

(13) Liang, Y.; Xu, Z.; Xia, J.; Tsai, S. T.; Wu, Y.; Li, G.; Ray, C.; Yu, L. For the Bright Future-Bulk Heterojunction Polymer Solar Cells with Power Conversion Efficiency of 7.4\%. Adv. Mater. 2010, 22, 135-138.

(14) Brady M.A.; Su G.M.; Chabinyc M.L. Recent Progress in the Morphology of Bulk Heterojunction Photovoltaics. Soft Matter. 2011, 7, 11065-11077.

(15) Hammed W.A.; Yahya R.; Bola A.L.; Ekramul Mahmud H.N.M. Recent Approaches to Controlling the Nanoscale Morphology of Polymer-Based Bulk-Heterojunction Solar Cells. Energies 2013, 6, 5847-5868.

(16) Xue R.; Zhang J.; Li Y.; Li Y. Organic Solar Cell Materials toward Commercialization. Small 2018, 1801793. 
(17) Di Nuzzo, D.; Aguirre, A.; Shahid, M.; Gevaerts, V.S.; Meskers, S.C.J.; Janssen, R.A.J. Improved Film Morphology Reduces Charge Carrier Recombination into the Triplet Excited State in a Small Bandgap Polymer-Fullerene Photovoltaic Cell. Adv. Mater. 2010, 22, 43214324.

(18) Collins B.A.; Li Z.; Tumbleston J.R.; Gann E.; McNeill C.R.; Ade H. Absolute Measurement of Domain Composition and Nanoscale Size Distribution Explains Performance in PTB7:PC 71 BM Solar Cells. Adv. Energy Mater., 2013, 3, 65-74.

(19) Min J.; Jiao X.; Ata I.; Osvet A.; Ameri T.; Bäuerle P.; Ade H.; Brabec C.J. TimeDependent Morphology Evolution of Solution-Processed Small Molecule Solar Cells during Solvent Vapor Annealing. Adv. Energy Mater., 2016, 6, 1502579.

(20) Wessendorf C.D.; Perez-Rodriguez A.; Hanisch J.; Arndt A. P.; Ata I.; Schulz G.L.; Quintilla A.; Bäuerle P.; Lemmer U.; Wochner P.; Ahlswede E.; Barrena E. Understanding the Effect of Solvent Vapor Annealing on Solution-Processed A-D-A Oligothiophene BulkHeterojunction Solar Cells: The Role of Alkyl Side Chains. J. Mater. Chem. A, 2016, 4, 25712580 .

(21) Hu, H.; Jiang, K.; Chow, P.C.Y.; Ye, L.; Zhang, G.; Li, Z.; Carpenter J.H.; Ade H.; Yan H. Influence of Donor Polymer on the Molecular Ordering of Small Molecular Acceptors in Nonfullerene Polymer Solar Cells. Adv. Energy Mater. 2017, 8, 1701674.

(22) Zhu Y.; Gadisa A.; Peng Z.; Ghasemi M.; Ye L.; Xu Z.; Zhao S.; Ade H. Rational Strategy to Stabilize an Unstable High-Efficiency Binary Nonfullerene Organic Solar Cells with a Third Component. Adv. Energy Mater. 2019, 9, 1900376.

(23) Song L.; Wang W.; Barabino E.; Yang D.; Körstgens V.; Zhang P.; Roth S. V.; MüllerBurschbaum P. Composition-Morphology Correlation in PTB7-Th/PC $\mathrm{P}_{71} \mathrm{BM}$ Blend Films for Organic Solar Cells. ACS Appl. Mater. Interfaces 2019, 11, 3125-3135.

(24) Pfannmöller M.; Kowalsky W.; Schröder R.R. Visualizing Physical, Electronic, and Optical Properties of Organic Photovoltaic Cells. Energy \& Environ. Sci. 2013, 6, 2871-2891.

(25) Pfannmöller M.; Flügge H.; Benner G.; Wacker I.; Sommer C.; Hanselmann M.; Schmale S.; Schmidt H.; Hamprecht F.A.; Rabe T.; Kowalsky W.; Schröder R.R. Visualizing a Homogeneous Blend in Bulk Heterojunction Polymer Solar Cells by Analytical Electron Microscopy. Nano Letters 2011, 11, 3099-3107.

(26) Wen J.; Miller D.J.; Chen W.; Xu T.; Yu L.; Darling S.B.; Zaluzec N.J. Visualization of Hierarchical Nanodomains in Polymer/Fullerene Bulk Heterojunction Solar Cells. Microsc. Microanal. 2014, 20, 1507-1513.

(27) Moritomo, Y.; Yasuda, T.; Yonezawa, K.; Sakurai, T.; Takeichi, Y.; Suga H.; Takahashi Y.; Inami, N.; Mase, K.; Ono, K. Fullerene Mixing Effect on Carrier Formation in Bulk-Hetero Organic Solar Cell. Sci. Rep. 2015, 5, 9483.

(28) Ben Dkhil, S.; Pfannmöller, M.; Schröder, R. R.; Alkarsifi, R.; Gaceur, M.; Köntges, W.; Heidari, H.; Bals, S.; Margeat, O.; Ackermann, J.; Videlot-Ackermann C. Interplay of Interfacial 
Layers and Blend Composition To Reduce Thermal Degradation of Polymer Solar Cells at High Temperature. ACS Appl. Mater. Interfaces 2018, 10, 3874- 3884.

(29) Ben Dkhil, S.; Pfannmöller, M.; Saba, M. I.; Gaceur, M.; Heidari, H.; VidelotAckermann, C.; Margeat, O.; Guerrero, A.; Bisquert, J.; Garcia-Belmonte, G.; Mattoni A.; Bals S.; Ackermann J. Toward High-Temperature Stability of PTB7-Based Bulk Heterojunction Solar Cells: Impact of Fullerene Size and Solvent Additive. Adv. Energy Mater. 2017, 7, 1601486.

(30) Köntges, W.; Perkhun, P.; Kammerer, J.; Alkarsifi, R.; Würfel, U.; Margeat, O.; VidelotAckermann, C.; Simon, J.-J.; Schröder, R.; Ackermann, J.; Pfannmöller, M. Visualizing Morphological Principles for Efficient Photocurrent Generation in Organic Non-fullerene Acceptor Blends. Energy Environ. Sci., 2020, 13, 1259-1268.

(31) He Z.; Zhong C.; Su S.; Xu M.; Wu H.; Cao Y. Enhanced Power-Conversion Efficiency in Polymer Solar Cells Using an Inverted Device Structure. Nat. Photon. 2012, 6, 591-595.

(32) To C.H.; Ng A.; Dong Q.; Djurišić A. B.; Zapien J. A.; Chan W. K.; Surya C. Effect of PTB7 Properties on the Performance of PTB7:PC 71 BM Solar Cells. ACS Appl. Mater. Interfaces, 2015, 7, 13198-13207.

(33) Liu, C.; Wang, K.; Hu, X.; Yang, Y.; Hsu, C.-H.; Zhang, W.; Xiao, S.; Gong, X.; Cao, Y. Molecular Weight Effect on the Efficiency of Polymer Solar Cells. ACS Appl. Mater. Interfaces 2013, 5, 12163-12167.

(34) Lou S. J.; Szarko J. M.; Xu T.; Yu L. P.; Marks T. J.; Chen L. X. Effects of Additives on the Morphology of Solution Phase Aggregates Formed by Active Layer Components of HighEfficiency Organic Solar Cells. J. Am. Chem. Soc. 2011, 133, 20661-20663.

(35) Kim W.; Kim J. K.; Kim E.; Ahn T. K.; Wang D. H.; Park J. H. Conflicted Effects of a Solvent Additive on PTB7:PC 71 BM Bulk Heterojunction Solar Cells. J. Phys. Chem. C 2015, $119,5954-5961$.

(36) Wang L.; Zhao S. L.; Xu Z.; Zhao J.; Huang D.; Zhao L. Integrated Effects of Two Additives on the Enhanced Performance of PTB7:PC 71 BM Polymer Solar Cells. Materials 2016, 9, 171 .

(37) Chen H.-Y.; Lin S. H.; Sun J.Y.; Hsu C.-H.; La S.; Lin C.-F. Morphologic Improvement of the PBDTTT-C and $\mathrm{PC}_{71} \mathrm{BM}$ Blend Film with Mixed Solvent for High-Performance Inverted Polymer Solar Cells. Nanotechnology 2013, 24, 484009.

(38) Alem S.; Chu T.; Tse S. C.; Wakim S.; Lu J.; Movileanu R.; Tao Y.; Bélanger F.; Désilets D.; Beaupré S.; Leclerc M.; Rodman S.; Waller D.; Gaudiana R. Effect of Mixed Solvents on PCDTBT:PC 70 BM Based Solar Cells. Org. Electron. 2011, 12, 1788-1793.

(39) Wang G. J.; Jiu T. G.; Tang G.; Li J.; Li P. D.; Song X. J.; Lu F. S.; Fang J. F. Interface Modification of ZnO-Based Inverted PTB7:PC 71 BM Organic Solar Cells by Cesium Stearate and Simultaneous Enhancement of Device Parameters. ACS Sustainable Chem. Eng. 2014, 2, 13311337. 
(40) Lu Y.; Xu T.; Jung I.H.; Yu L. Match the Interfacial Energy Levels Between Hole transport Layer and Donor polymer to Achieve High Solar Cell performances. J. Phys. Chem. C 2014, 118, 22834-22839.

(41) Kniepert J.; Lange I.; Heidbrink J.; Kurpiers J.; Brenner T.J.K.; Koster L.J.A.; Neher D. Effect of Solvent Additive on Generation, Recombination, and Extraction in PTB7:PCBM Solar Cells: A Conclusive Experimental and Numerical Simulation Study. J. Phys. Chem. C 2015, 119, 8310-8320.

(42) Guerrero A.; Garcia-Belmonte G. Recent Advances to Understand Morphology Stability of Organic Photovoltaics. Nano-Micro Lett. 2017, 9:10.

(43) Guo, J. C.; Liang, Y. Y.; Szarko, J.; Lee, B.; Son, H. J.; Rolczynski, B. S.; Yu, L. P.; Chen, L. X. Structure, Dynamics, and Power Conversion Efficiency Correlations in a New Low Bandgap Polymer: PCBM Solar Cell. J. Phys. Chem. B 2010, 114, 2, 742-748.

(44) Ho C.H.Y.; Cheung S.H.; Li H.-W.; Chiu K.L.; Cheng Y.; Yin H.; Chan M.H.; So F.; Tsang S.-W., So S.K. Using Ultralow Dosages of Electron Acceptor to Reveal the Early Stage Donor-Acceptor Electronic Interactions in Bulk Heterojunction Blends. Adv. Energy Mater. 2017, 1602360.

(45) Dkhil, S. B.; Duché, D.; Gaceur, M.; Thakur, A. K.; Aboura, F.B.; Escoubas, L.; Simon, J.-J.; Guerrero, A.; Bisquert, J.; Garcia-Belmonte, G.; Bao Q.; Fahlman M.; Videlot-Ackermann C.; Margeat O.; Ackermann J. Interplay of Optical, Morphological, and Electronic Effects of $\mathrm{ZnO}$ Optical Spacers in Highly Efficient Polymer Solar Cells. Adv. Energy Mater. 2014, 4, 1400805.

(46) de la Peña F.; Prestat E.; Fauske V.T.; Burdet P.; Jokubauskas P.; Nord M.; Garmannslund A.. (2019, September 6). hyperspy/hyperspy: HyperSpy v1.5.2 (Version v1.5.2). Zenodo. http://doi.org/10.5281/zenodo.3396791.

(47) Newville M.; Otten R.; Nelson A.; Ingargiola A.; Stensitzki T.; Allan D.; Almarza A. (2020, May 7). lmfit/lmfit-py 1.0.1 (Version 1.0.1). Zenodo. http://doi.org/10.5281/zenodo.3814709.

(48) Blakesley J.C.; Castro F.; Kylberg W.; Dibb G. F.A.; Arantes C.; Valaski R.; Cremona M.; Kim J. S.; Kim J.-S. Towards Reliable Charge-Mobility Benchmark Measurements for Organic Semiconductors. Org. Electronics 2014, 15, 1263-1272.

(49) Wang J.; Wolf R.M.; Caldwell J.W.; Kollman P.A.; Case D.A. Development and Testing of a General Amber Force Field. J. Comput. Chem. 2004, 25, 1157-1174.

(50) Mattioli, G.; Ben Dkhil, S.; Saba G.I.; Malloci G.; Melis C.; Alippi P.; Filippone F.; Thakur A.K.; Gaceur M.; Margeat O.; Diallo A.K.; Videlot-Ackermann C.; Ackermann J.; Bonapasta A.A.; Mattoni A. Interfacial Engineering of P3HT/ZnO Hybrid Solar Cells Using Phthalocyanines: A Joint Theoretical and Experimental Investigation. Adv. Energy Mater. 2014, 4,1301694. 
(51) Caddeo C.; Fazzi D.; Caironi M.; Mattoni A. Atomistic Simulations of P(NDI2OD-T2) Morphologies: From Single Chain to Condensed Phases. J. Phys. Chem. B 2014, 43, 1255612565 .

(52) Caddeo C.; Dessì R.; Melis C.; Colombo L.; Mattoni A. Poly(3-hexylthiophene) Adhesion on Zinc Oxide Nanoneedles. J. Phys. Chem. C 2011115 (34), 16833-16837.

(53) Caddeo C.; Mattoni A. Atomistic Investigation of the Solubility of 3-Alkylthiophene Polymers in Tetrahydrofuran Solvent. Macromolecules 2013, 46 (19), 8003-8008.

(54) Phillips J.C.; Braun R.; Wang W.; Gumbart J.; Tajkhorshid E.; Villa E.; Chipot C.; Skeel R.D.; Kalé L.; Schulten K. Scalable Molecular Dynamics with NAMD. J. Comput. Chem. 2005, 26, 1781-802.

(55) Humphrey W.; Dalke A.; Schulten K. VMD: Visual Molecular Dynamics. J. Mol. Graphics 1996, 14, 33-38.

(56) Bellani S.; Porro M.; Caddeo C.; Saba M.I.; Miranda P.B.; Mattoni A.; Lanzani G.; Antognazza M.R. The Study of Polythiophene/Water Interfaces by Sum-Frequency Generation Spectroscopy and Molecular Dynamics Simulations. J. Mater. Chem. B 2015, 3, 6429-6438.

(57) Casalegno M.; Zanardi S.; Frigerio F.; Po R.; Carbonera C.; Marra G.; Nicolini T.; Raos G.; Meille S.V. Solvent-Free Phenyl-C61-Butyric Acid Methyl Ester (PCBM) from Clathrates: Insights for Organic Photovoltaics from Crystal Structures and Molecular Dynamics. Chem. Comm. 2013, 49, 4525-4527.

(58) Krone M.; Stone J.E.; Ertl T.; Schulten K. Fast Visualization of Gaussian Density Surfaces for Molecular Dynamics and Particle System Trajectoires. EuroVis - Short Papers 2012, 1, 67-71.

(59) Ebenhoch B.; Thomson S.A. J.; Genevičius K.; Juška G.; Samuel I.D.W. Charge Carrier Mobility of the Organic Photovoltaic Materials PTB7 and $\mathrm{PC}_{71} \mathrm{BM}$ and its Influence on Device Performance. Org. Electron. 2015, 22, 62-68.

(60) Hammond M.R.; Kline J.; Herzing A.A.; Richter L.J.; Germack D.S.; Ro H.-W.; Soles C.L.; Fischer D.A.; Xu T.; Yu L.; Toney M.F.; DeLongchamp D.M. Molecular Order in HighEfficiency Polymer/Fullerene Bulk Heterojunction Solar Cells. ACS Nano 2011, 5, 8248-8257.

(61) Guerrero A.; Pfannmoller M.; Kovalenko A.; Ripolles T.S.; Heidari H.; Bals S.; Kaufmann L.-D.; Bisquert J.; Garcia-Belmonte G. Nanoscale Mapping by Electron Energy-Loss Spectroscopy Reveals Evolution of Organic Solar Cell Contact Selectivity. Org. Electron. 2015, $16,227-233$.

(62) Lou S.J.; Szarko J.M.; Xu T.; Yu L.P.; Marks T.J.; Chen L.X. Effects of Additives on the Morphology of Solution Phase Aggregates Formed by Active Layer Components of HighEfficiency Organic Solar Cells. J. Am. Chem. Soc. 2011, 133, 20661-20663.

(63) Chen W.; Xu T.; He F.; Wang W.; Wang C.; Strzalka J.; Liu Y.; Wen J.; Miller D.J.; Chen J.; Hong K.L.; Yu L.; Darling S.B. Hierarchical Nanomorphologies Promote Exciton 
Dissociation in Polymer/Fullerene Bulk Heterojunction Solar Cells. Nano Lett. 2011, 11, 37073713.

(64) Deibel C.; Dyakonov V.; Brabec C.J. Organic Bulk-Heterojunction Solar Cells. IEEE J. Sel. Top. Quantum Electron. 2010, 16, 1517-1527.

(65) Shaw, P. E.; Ruseckas, A.; Samuel, I. D. W. Exciton Diffusion Measurements in Poly(3hexylthiophene). Adv. Mater. 2008, 20, 3516-3520.

(66) Foster S.; Deledalle F.; Mitani A.; Kimura T.; Kim K.-B.; Okachi T.; Kirchartz T.; Oguma J.; Miyake K.; Durrant J.R.; Doi S.; Nelson J. Electron Collection as a Limit to Polymer:PCBM Solar Cell Efficiency: Effect of Blend Microstructure on Carrier Mobility and Device Performance in PTB7:PCBM. Adv. Energy Mater. 2014, 4, 1400311.

(67) Zhou N.; Lin H.; Lou S.J. ; Yu X.; Guo P.; Manley E.F.; Loser S.; Hartnett P.; Huang H.; Wasielewski M.R.; Chen L.X.; Chang R.P.H.; Facchetti A.; Marks T.J. MorphologyPerformance Relationships in High-Efficiency All-Polymer Solar Cells. Adv. Energy Mater. 2014, 4, 1300785.

(68) Uy R.L.; Price S.C.; You W. Structure-Property Optimizations in Donor Polymers via Electronics, Substituents, and Side Chains toward High Efficiency Solar Cells. Macromol. Rapid Commun. 2012, 33, 1162-1177.

(69) Ho C.H.Y.; Dong Q.; Yin H.; Leung W.W.K.; Yang Q.; Lee H.K.H.; Tsang S.W.; So S.K. Impact of Solvent Additive on Carrier Transport in Polymer:Fullerene Bulk Heterojunction Photovoltaic Cells. Adv. Mater. Interfaces 2015, 2, 1500166. 


\section{Graphical abstract}

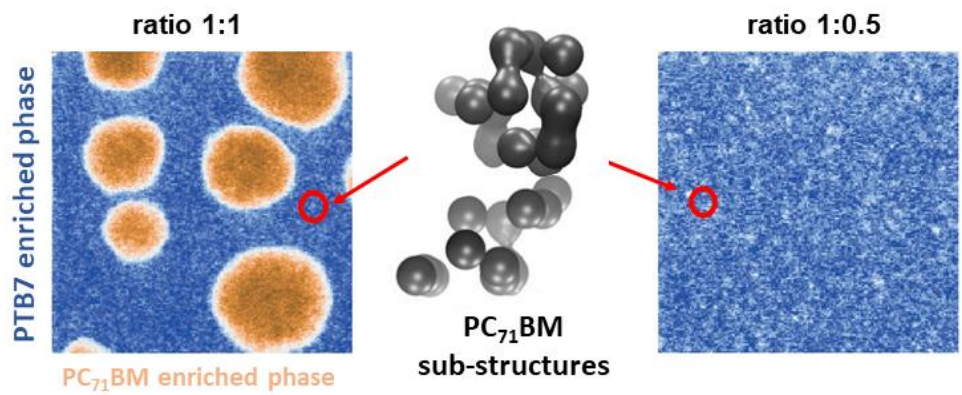

